\author{
Juan Carlos Guerra Velasco
}

Departamento de Geografía. Universidad de Valladolid [guerra@geo.uva.es]

\title{
De «oro marrón» a patrimonio olvidado: explotación forestal y negocio corcho-taponero en Liébana (Cantabria)'
}

\section{RESUMEN}

El perfil forestal de Cantabria se construye en la actualidad tanto en torno a la producción de madera como sobre la presencia de dos espacios forestales: el de la selva atlántica y el de la silvicultura intensiva. Estos rasgos disimulan el significado local que tienen o tuvieron otras actividades en la conformación de la identidad forestal de ese ámbito. Es el caso del negocio corcho-taponero en Liébana, en cuyo nacimiento hay fuertes elementos de originalidad y cuyo desarrollo posterior, siempre sin superar la dimensión del pequeño taller artesanal, está marcado por las limitaciones de los alcornocales lebaniegos para la producción de materia prima.

\section{RÉsUMÉ}

De «l'or brun» à patrimoine oublié: l'exploitation forestière et l'industrie du liège dans Liébana (Cantabria-Espagne).- Le profil de la forêt de Cantabrie (Espagne) se construit actuellement autour de la production de bois et la présence de deux zones forestières: la forêt atlantique et la sylviculture intensive. Ces traits cachent l'importance locale qui ont ou avaient autres activités dans le façonnement de l'identité de cette zone forestière. C'est le cas de l'entreprise de liège près de Liébana qui avait dans sa naissance des éléments de vraie originalité.

\section{INTRODUCCIÓN}

$L$ os alcornocales de Liébana (Cantabria) no necesitan presentación. Su ubicación en el límite norte del

\footnotetext{
${ }^{1}$ Este texto es un resultado parcial de la xI beca de investigación del Museu del Suro de Palafrugell con el trabajo En los márgenes del mundo corchero: la producción, transformación y comercialización del corcho en el noroeste de España. También lo es del proyecto Paisajes patrimoniales de España (Ministerio de Economía y Competitividad, CSO2012-39564-C07-01).
}

Son développement, qui n'avait pas dépassé la dimension du petit atelier, est marqué par les limites des forêts de chêne liège de Liébana pour la production de matières premières.

\section{ABSTRACT}

From «the brown gold» to forgotten heritage: forest exploitation and cork industry in Liebana (Cantabria-Spain).- Cantabria forest profile is currently built round the production of wood as well as around the presence of two forest spaces: the Atlantic rainforest and the intensive forestry. These features tone down the local role that other activities have or had in shaping the forest identity of this area. A case in point is the cork industry in Liébana (Spain) whose origin is marked by strongly original traits. Its later development did never exceed the limits of small handmade family industries and is constrained by the limitations of cork oak forests in Liébana for the production of raw material.

Palabras Clave/Mots clé/Keywords

Tapón, corcho, industria rural, historia forestal. Bouchon, liège, industrie rurale, histoire de la forêt. Sttoper, cork, rural industry, forest history.

área de distribución ibérica de esta especie hace que su presencia no haya pasado inadvertida para la literatura geobotánica y forestal española (Guinea, 1953; Bertrand, 1964; Díaz y otros, 1996 y Costa y otros, 1997) (Fig. 1). No ocurre lo mismo con su explotación; y eso a pesar de que los alcornocales lebaniegos poseen, como los del resto de España, una carta de presentación bien visible: la huella de los descorches.

Quizá la razón haya que buscarla en el hecho de que dos construcciones dominan el espacio forestal de Can- 


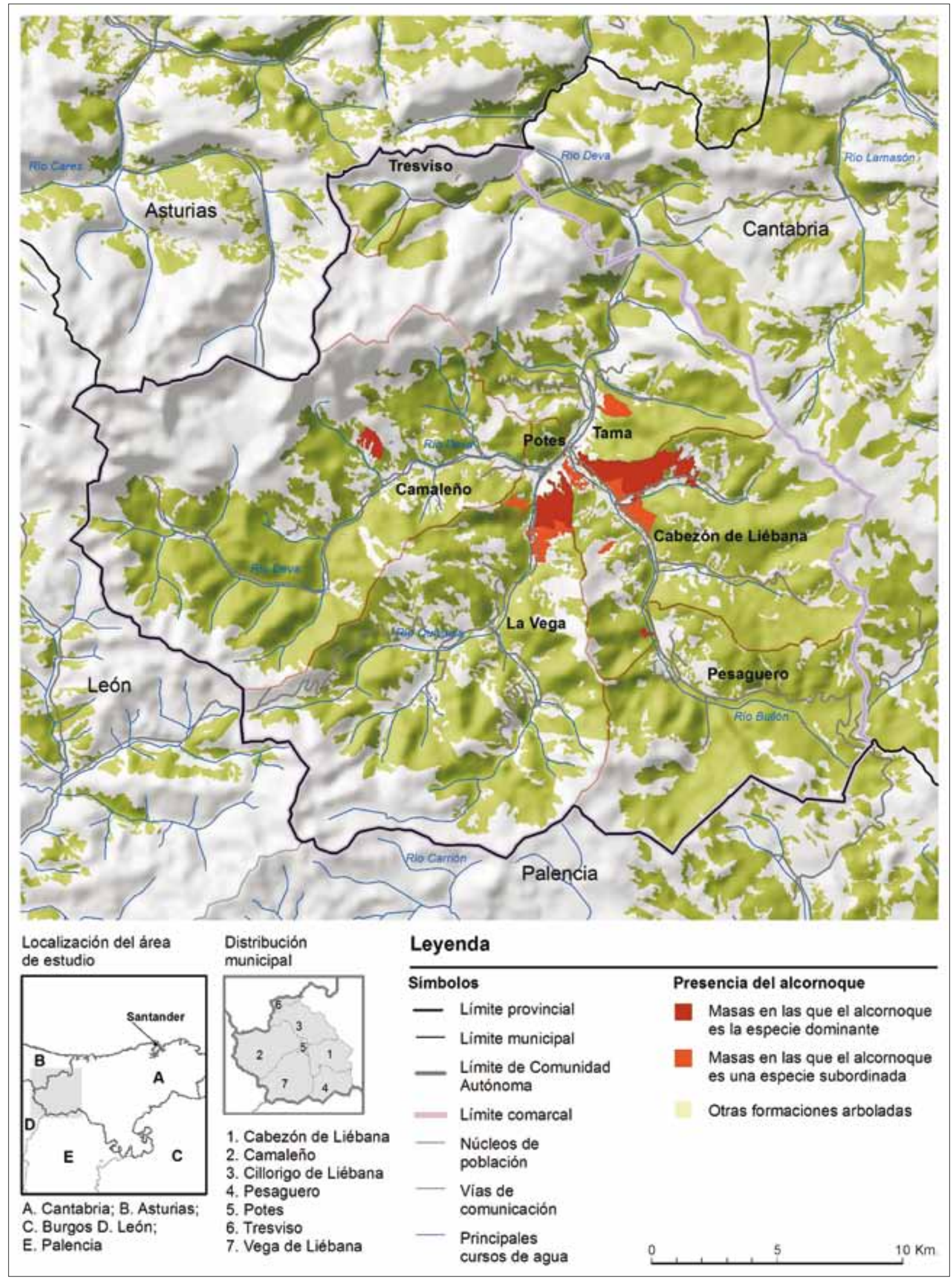

FIG. 1. Distribución de las masas de alcornoque en Liébana (Cantabria). 
tabria: el paisaje de la selva atlántica y el de la silvicultura intensiva. En torno a ellos se ha armado el grueso del discurso forestal y frente a ellos empequeñece cualquier otra manifestación y actividad. Es el caso de los alcornocales lebaniegos. Ocupan unas 1.140 ha (MFE50) y sus menguadas producciones de corcho contrastan vivamente con la magnitud que tiene, por ejemplo, la extracción de maderas ${ }^{2}$. Además, desde hace ya décadas no se elabora en Liébana ningún tipo de género corchero y, olvidada la operación y el oficio de pelar un alcornoque, los adjudicatarios extremeños de los aprovechamientos de corcho que ocasionalmente se realizan recurren a sus propios operarios para este trabajo. No obstante, hubo un momento en que en el corcho lebaniego, al calor del capitalismo forestal que recorría las montañas españolas en el siglo XIX y de las propias condiciones en las que se desenvolvía la comarca, se depositaron no pocas esperanzas de progreso y enriquecimiento.

El intervalo temporal acotado por este trabajo comienza con la llegada a Liébana en las primeras décadas del siglo XIX de un nuevo paradigma en el aprovechamiento del corcho, el de su uso industrial y taponero y acaba en tiempos recientes ${ }^{3}$. Sobre este intervalo es necesario proyectar tres miradas interrelacionadas (la dimensión productora, el estado silvícola y las actividades de transformación y comercialización del corcho) y entender las lógicas de tres grandes tipos de agentes: los propietarios de los montes alcornocales (ayuntamientos y juntas vecinales), los industriales taponeros y, por último, la administración forestal.

Recomponer esa historia exige combinar el trabajo de campo con el archivístico y documental. El primero tiene por objetivo reconocer los distintos alcornocales lebaniegos y entrevistar a quienes todavía guardan recuerdos de las pequeñas industrias que éstos alimentaron. El segundo es más complejo, sobre todo porque la primera impresión al enfrentarse a este objeto de estudio es el de su invisibilidad documental. Las obras que tratan sobre el corcho y el tapón, empezando por la clásica de Ramiro Medir de 1953, sólo aportan algunas referencias puntuales y vagas; y otras, si bien tienen el valor indudable de haber construido un mínimo retrato de esta actividad y

\footnotetext{
${ }^{2}$ El cálculo de la superficie ocupada por el alcornoque no es sencillo, sobre todo por el grado de mezcla que presenta con otras especies. De esas 1.140 ha, en unas 350 es la especie dominante (Díez, 2002).

${ }^{3}$ Para profundizar en las lógicas y en la historia del negocio corcho-taponero español es obligada la consulta, entre otras, de las obras de Alvarado (2002); Jiménez (1999, 2009 y 2013); Medir (1953); Parejo (2010); Parejo y otros (2013); Sala (1998); Sala y Nadal (2010) y Zapata (1986, 1996 y 2009).
}

de ser un punto de partida en el que iniciar una investigación, en realidad reproducen las referencias contenidas en los proyectos de ordenación que se elaboran en los años setenta del siglo $\mathrm{xx}$ de los montes de utilidad pública donde se ubican los alcornocales (Aedo y otros, 1990, y Ezquerra y Gil, 2004).

La información más valiosa se encuentra en el Archivo de la Dirección General de Montes y Conservación de la Naturaleza del Gobierno de Cantabria. Se compone de una caja sin numerar, denominada «corcho» y aparecida a lo largo de esta investigación, que en apariencia contiene toda la documentación que sobre este asunto genera el antiguo Distrito Forestal de Santander desde 1907 hasta 1960. A esta caja se le añaden los proyectos de ordenación antes enunciados, sus revisiones y los estudios técnicos más recientes.

El Fondo Montes del siglo xIX y el de Repoblaciones, Deslindes y Amojonamientos del Archivo Central del Ministerio de Agricultura ayudan a entender diversos aspectos de la gestión y explotación de los alcornocales lebaniegos en el último cuarto del siglo XIX y primeros años del xx. Una función semejante posee la documentación del Archivo Histórico Provincial de Cantabria, especialmente la de su sección Montes-Diputación. Otro archivo de interés es el de la Cámara de Comercio de Cantabria. En él se encuentran los censos repartimiento o censos de electores que recogen, por municipio, la actividad por la que cada industrial tributa en la cámara. A falta de otra fuente de información, ayudan a reconstruir el número y evolución de los talleres de transformación del corcho, aunque en este caso sólo en un corto periodo: entre 1928 y 1937. Vinculado con la figura del industrial taponero está el uso que se ha dado a los fondos del Archivo Histórico Diocesano de Santander, concretamente los libros sacramentales de la parroquia de Potes. Aunque los párrocos no siempre indican la profesión de los padres, esposos y finados en los libros de bautizos, casados y difuntos son útiles para encontrar la primera referencia al oficio de corchero o taponero.

De gran ayuda, centrales más bien, deberían haber sido los archivos municipales y los de las juntas vecinales. Sin embargo, muchos de ellos desaparecieron o sufrieron no pocos daños a lo largo del siglo xIx y la guerra civil, y los que se conservan no se encuentran catalogados. En la práctica, junto con un peculiar sentido de la administración, es imposible o extremadamente dificultosa la consulta de la información contenida en ellos. No ocurre lo mismo con los fondos de la Fundación de los Ferrocarriles Españoles. La documentación de interés se reduce a unos pocos documentos, pero aun así relevantes 
para reconstruir algunos de los caminos que toma el corcho lebaniego hacia el resto de España en los años treinta del siglo $\mathrm{xx}$.

Por último, es necesario mencionar la consulta de los fondos de la Biblioteca Municipal de Santander y la particular de Eduardo García de Enterría. La primera es indispensable para acceder, a través de sus memorias anuales, a la labor que realiza la Sociedad Económica de Amigos del País de Liébana en las décadas centrales del siglo XIX y a la prensa local lebaniega. En ésta destaca $L a$ Voz de Liébana, cuya colección completa se consultó gracias a la amable colaboración del recientemente fallecido Eduardo García de Enterría.

\section{ABASTECER A FRANCIA: EL ORIGEN DEL APROVECHAMIENTO MODERNO DEL CORCHO EN LIÉBANA}

Matías Lamadrid, en su obra de 1836 sobre los montes de Liébana, relata los inicios del comercio del corcho en esa parte del norte de España. Su origen lo sitúa en la llegada de un comerciante francés en 1827 (parece razonable pensar que hubiese algún viaje de tanteo previo) que se hizo con el aprovechamiento de corcho. Una vez empaquetado, lo lleva a través «desperados» caminos de montaña hasta el puerto de Santander, desde donde sale hacia el francés de Bayona, quizá para alimentar los talleres taponeros de la pequeña región del Marensin (sur de Aquitania), que por esas fechas se nutren básicamente del corcho importado a través de aquel puerto $\left(\right.$ Puyo, 2010) ${ }^{4}$. El proporciona la contabilidad somera de este trajín comercial: después de todas las operaciones de pela y transporte, el francés obtiene más de «1.000 duros netos» de beneficio con la venta del corcho (Lamadrid, 1836, p. 59).

Esta etapa inicial caracterizada por el perfil extravertido de la economía y la actividad corchera de Liébana parece que concluye hacia 1840 . Una de las pocas memorias que edita la Sociedad Económica de Amigos del País de Liébana da la noticia de la apertura de un nuevo camino de rueda a través del desfiladero de La Hermida hasta un punto que permite la llegada de barcas de fondo plano y el transporte de corcho hacia la marina de Unquera, cerca ya de la costa. Este camino hace más atractivo el comer-

\footnotetext{
${ }^{4}$ El recorrido, dado que no era posible bajar hacia el mar a través del desfiladero de La Hermida siguiendo el río Deva, implicaba salvar el puerto de Piedraluengas o el de Sierras Albas y desde allí buscar el río Besaya para llegar hasta el puerto de Santander.
}

cio corchero (tiene menos riesgo el transporte y mejora el beneficio), a la vez que el contacto durante las décadas precedentes con los compradores franceses de corcho sin duda despierta el interés, vista la rentabilidad, de gentes del lugar. Éstos proceden a arrendar en 1840 montes de alcornoque en Frama, Cambarco, Argüévanes y Tanarrio y provocan que «los franceses venidos este año [1840] á comprar corcho ya no lo pudieron conseguir, y que algunos en esta villa [la memoria se refiere a Potes] han empezado á cocerle y trabajarle» (SEAPL, 1841, p. 11).

En este punto conviene introducir un matiz. En realidad, se puede señalar que el protagonismo francés se extiende más allá de 1840. Pedro Estanquet es la primera persona que aparece citada como «que se egercita en las labores de corcho para tapones», al quedar constancia de su profesión después de bautizar a una hija en 1844 (ADS, Libro de Bautizos, sig. 945). Es natural de una localidad cercana a Bayona, al igual que un tal Pedro Irigoyen, un curtidor afincado en Potes, que bautiza en Liébana a su primera hija en 1832 y que aparece mencionado unos años más tarde (1847 y 1851) en varias compras de corcho (ADS, Libro de Bautizos, sig. 944, y AHPCA, sección Diputación-Montes, legajo 7 , núm. 2) $)^{5}$. Lo que sí que parece indudable es que a partir de ese momento aparecen nuevos agentes en la actividad corchera lebaniega, a la vez que se convierte en un objeto de promoción, bien llevando muestras de corcho a los escaparates con mayor proyección de la época (ferias y certámenes agropecuarios) o bien emprendiendo actuaciones que pretenden tener un calado más profundo. El mejor ejemplo es el proporcionado por la Sociedad Económica de Amigos del País de Liébana.

\section{LA SOCIEDAD ECONÓMICA DE AMIGOS DEL PAÍS DE LIÉBANA Y LA PROMOCIÓN DEL NEGOCIO CORCHERO}

La Económica, como se la conoce popularmente, nace en 1839 de la mano de algunos propietarios, miembros de la administración, comerciantes y profesionales liberales de Liébana, principalmente de Potes, en un momento de renacimiento generalizado de este tipo de entidades al amparo de la real orden de 18 de mayo de 1834 sobre Establecimiento de Sociedades Económicas. El ideario económico de quienes la componen pasa por

\footnotetext{
${ }^{5}$ En el caso de Pedro Irigoyen se puede pensar que el oficio de curtidor le pone en contacto con las posibilidades forestales de Liébana.
} 
el deseo de reproducir los capitales que obtienen con la venta de tierras a través de la transformación de la comarca en un espacio productor de materias primas, sobre todo madera (Lanza, 1988). Su vida, con altibajos, se prolonga hasta el comienzo de la guerra civil, enfrentamiento que conlleva la destrucción (a veces apropiación) de la práctica totalidad del fondo documental de La Económica. La información sobre sus trabajos proviene de algunos documentos impresos (estatutos y unas pocas memorias de actividad) y de las noticias que sobre ella incorpora a partir de 1904 y hasta $1932 \mathrm{La} \mathrm{Voz}$ de Liébana, periódico comarcal que actúa como su medio oficioso de comunicación.

En esa «reunión de individuos dedicada á promocionar la agricultura, las artes, el comercio y las ciencias útiles para el país», tal y como reza el artículo primero de sus estatutos, destaca inicialmente Matías Lamadrid, perfecto conocedor de la riqueza forestal de Liébana (no en vano escribe una memoria sobre ella y un hermano es visitador de montes), y no es descabellado adjudicarle a él los iniciales intentos por dar a conocer, extender y modernizar el trabajo del corcho que emprende La Económica. Ésta ve en el corcho una oportunidad de envergadura para el progreso de los pueblos de Liébana y es de suponer que también para el enriquecimiento personal. La memoria de actividades de 1840 proporciona información suficiente para reconstruir los empeños iniciales de la sociedad. Ésos toman dos caminos relacionados: actuar sobre el espacio productor, el alcornocal, y favorecer el desarrollo de iniciativas transformadoras del corcho. Sin embargo, para afrontar con ciertas garantías de éxito el trabajo en esas dos líneas, La Económica cree necesario ampliar los conocimientos que tiene sobre la silvicultura del alcornoque y el laboreo del corcho. Lo intenta con un cuestionario de veintiséis preguntas que se traslada a la Sociedad Económica de Cantabria y, a través del jefe político de la provincia de Santander, a los cónsules de España en Bayona y Marsella ${ }^{6}$. Se consiguen las respuestas del primero, pero no las del segundo, aunque éstas son sustituidas por una información que obtiene el director de la Sociedad Económica de Cantabria. A estos interrogatorios se suma un informe «más estenso y luminoso que los otros [pues] reúne láminas de tapones y herramientas tan deseadas» que proporciona

\footnotetext{
${ }^{6}$ Es significativo el hecho de que no se dirija ninguna pesquisa hacia Cataluña, aunque luego hubo datos de este espacio, lo que sin duda está marcado tanto por el contacto inicial con los comerciantes franceses como por el desconocimiento del peso del alcornocal en determinadas comarcas de Gerona y de la pujanza que allí posee la elaboración de tapones.
}

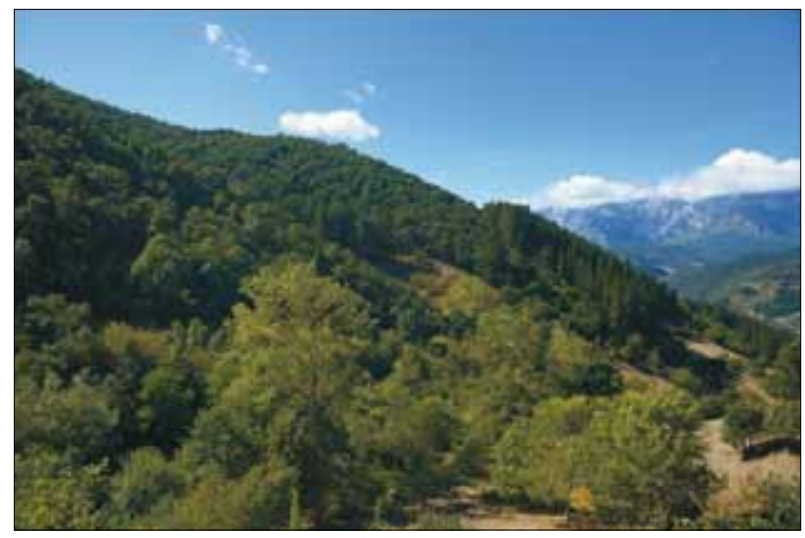

FIG. 2. Alconocal de Tolibes, en el municipio de Potes, con algunas repoblaciones de pino de Monterrey.

espontáneamente un comercial santanderino (SEAPL, 1841, pp. 11-12). La información sirve para que La Económica haga propuestas en los campos de la silvicultura y la industria.

La memoria de actividades de 1840 indica que los alcornocales lebaniegos son «formales selvas». Para que dejen de serlo o, mejor dicho, para saber cómo se puede realizar el tránsito entre ésas y un verdadero bosque productor, La Económica cree obligado establecer un «monte modelo» en donde «ensayar los conocimientos y prácticas para su mejor cultivo [el del alcornoque]» (SEAPL, 1841, p. 11). El lugar en el que inicialmente se piensa es en un «estremo del de alcornoque [...] llamado Camarines», en el monte de Tolibes (Potes). Se estima que los trabajos que en él se ejecuten pueden ser una «operación práctica al alcance de todos» (los pueblos cercanos). En este sentido, y sin estar directamente relacionado con la puesta en marcha del alcornocal modelo, la sociedad solicita a los ayuntamientos de Liébana que limpien y acoten al pasto una parte de sus montes, preferiblemente los montes bajos de alcornoque, encina y roble. La petición es recogida por regidores como los de Potes y Pesagüero, que limpian «millares de alcornoques y encinas» (SEAPL, 1841, p. 13) (Fig. 2). La segunda de las líneas es menos concreta. Se pretende poner a disposición de los que se dediquen al laboreo del corcho la información obtenida en los cuestionarios, sobre todo las láminas de tipos de herramientas y clases de tapones. Éstas proporcionan una referencia de lo que el mercado demanda, más allá del corcho cocido, y de cómo elaborarlo.

El horizonte que la Sociedad Económica busca lo señala la memoria con claridad cuando, uniendo datos del momento con futuribles, dice que: 
[...] varios del país han empezado a arrendar montes de alcornoque, con grande interés de estos y de sus dueños, los pueblos, que como Frama, Cambarco, Argüevanes y Tanarrio recibirán desde el inmediato cantidades que nunca percibieron, sobre la notable ventaja de encontrar sus montes limpios, poblados, y en estado ascendente de producción al fenecerse el arriendo [...] á la mayor riqueza que cada año sucesivo deben los montes mejor administrados producir este artículo en bruto, se reunirá la que, ocupando bastante brazos en su laboreo, debe dejar el país tan apreciada industria. (SEPAL, 1841, p. 12)

Por otro lado, y como complemento, La Económica aporta muestras de corcho a la Exposición Nacional de Agricultura de 1857 y, más tarde, a la Exposición Vinícola Nacional de 1877, celebrada ambas en Madrid (Catálogo, 1857, 92-93; Exposición, 1877, 806). A la primera concurre con una representación suficiente de corcho y tapones como para poder valorar la calidad del corcho lebaniego, los géneros que salen de sus talleres y los precios a los que se colocan en el mercado. La asistencia a la Exposición Vinícola Nacional es distinta. Se viaja a ella con un reducido muestrario, aunque se señala la existencia de un representante en Madrid para todo tipo de transacciones comerciales.

La desaparición de la documentación de La Económica dificulta hacer una valoración certera del impacto que sus propuestas y actividades tienen en la actividad corchera de Liébana. Los propios relatos de la sociedad muestran cómo la sustitución de los comerciantes franceses por otros locales, entre los que señala en 1841 a un tal Vicente Sierra, es independiente de las labores de promoción del corcho que decide emprender, y el origen francés del primer taponero del que se tienen noticias plantea la duda sobre si el oficio lo trajo consigo desde el vecino país o si de alguna manera lo desarrolla en su nueva condición de lebaniego.

Por otro lado, el discurso de La Económica no impregna a toda la comarca. Si los arriendos deben proporcionar a los pueblos cantidades que nunca percibieron, hacia 1847 se producen situaciones en las que se da a entender que determinados concejos (los propietarios de los montes) desconocen el nuevo valor del corcho; y esa falta de información hace que la relación entre ellos y los tratantes de esa materia prima sea notablemente asimétrica, como ocurre en esas fechas entre Pedro Irigoyen y el concejo de Yebes (AHPCA, sección Diputación, Serie Montes; legajo 7, núm. 2).

Con la muerte de Matías Lamadrid en 1870, La Económica entra en un período de letargo del que sólo sale en los primeros años del siglo xx. El nuevo ciclo conlleva no obstante una notable disminución en la capacidad de hacer propuestas forestales por parte de la sociedad y, por ende, en todo lo relativo al binomio alcornoquecorcho. La memoria de actividades de 1909 tan sólo contiene, con motivo de la participación de miembros de la asociación en el VII Congreso de la Federación Agrícola de Castilla La Vieja, algunas vagas reflexiones forestales sobre la necesidad de una guardería forestal, el influjo benéfico de las repoblaciones forestales o la conveniencia de incluir éstas en la instrucción pública (SEAPL, 1909, p. 9).

La Voz de Liébana no se hace eco de recoge ningún tipo de propuesta relacionada con el estímulo a la producción de corcho, aunque sí que recoge algunas noticias sobre el estado de los alcornocales y el negocio corchero. En 1907 publica que «la explotación de los montes de alcornoque aun en el estado de abandono en que se encuentran desde hace muchos años constituye un elemento no despreciable de riqueza en la producción lebaniega, y en ellos encuentran los pueblos un recurso y una ayuda para su exhausto erario», y en 1913 expone que «los montes de alcornoque se encuentran [...] bastante abandonada su administración y su explotación, no rinden el producto de corcho de que serían susceptibles y es de temer que poco a poco vayan desapareciendo» (LVL, 1907 y LVL, 1913, p. 25). Añade a esta última afirmación un dato: la existencia en Potes de una sola «fábrica de corcho que emplea un hombre y produce 120.000 piezas» (LVL, 1913, p. 28). En los años siguientes, el alcornoque sólo aparece en $\mathrm{La} \mathrm{Voz}$ de Liébana como sufridor de incendios forestales o de algunos desafueros en la extracción de leñas (LVL, 1922, 1923, 1927 y 1928).

A la pérdida de vitalidad de la Sociedad Económica de Amigos del País de Liébana contribuyen, junto con el decaimiento generalizado de este tipo de entidades, factores relacionados con la vida interna de la asociación (Arbeu, 2012). En el caso particular de la pérdida de capacidad propositiva en torno al corcho sólo se puede conjeturar. La entrada del corcho lebaniego en los circuitos comerciales españoles y, por ende, el conocimiento de la producción española en esta materia prima y de la dimensión, núcleos y modernidad de la industria transformadora en otros ámbitos sin duda tuvieron que resituar a La Económica en su discurso sobre el corcho. Esta materia nunca es, aunque pueda proporcionar ingresos significativos a algunos concejos, el oro marrón que dejan vislumbrar Matías Lamadrid y la Sociedad Económica en sus primeros años. Las limitaciones que para la producción de corcho introducen la montaña y el pequeño tamaño de los montes alcornocales hacen que la cantidad de corcho producida anualmente sólo 
CUADRo I. Número y propiedad de los talleres corcho-taponeros en Liébana (1841-1937)

\begin{tabular}{|c|c|c|c|c|c|c|c|c|c|}
\hline 1841 & 1844 & 1848 & 1882 & $1894-95$ & 1904 & 1913 & $1926-27$ & $1928-29$ & $1930-37$ \\
\hline 1 & 1 & 1 & 1 & 1 & 2 & 1 & 2 & 1 & 2 \\
\hline $\begin{array}{l}\text { Vicente } \\
\text { Sierra }\end{array}$ & $\begin{array}{c}\text { Pedro } \\
\text { Estanquet }\end{array}$ & & $\begin{array}{l}\text { Sociedad } \\
\text { Corchera }\end{array}$ & & & & $\begin{array}{l}\text { Antonio Paz (La } \\
\text { Bienganada) y } \\
\text { Álvaro Fernández }\end{array}$ & $\begin{array}{c}\text { Antonio } \\
\text { Paz (La } \\
\text { Bienganada) }\end{array}$ & $\begin{array}{c}\text { Antonio Paz (La } \\
\text { Bienganada) y } \\
\text { Justo Aldana }\end{array}$ \\
\hline
\end{tabular}

Fuente: 1841 (SEAPL, 1841); 1844 (ADS, 945); 1848 (AHPCA, sección Montes, legajo 16); 1882 (Llorente, 1882); 1894-1895 (Medir, 1953 ); 1904 (Memoria, 1905); 1913 (LVL, 1913); 1926-1937 (Cocican, diversos años).

pueda alimentar pequeñas iniciativas de perfil doméstico y artesanal.

\section{LA ELABORACIÓN DE GÉNEROS CORCHEROS: PEQUEÑOS INDUSTRIALES VENDEDORES DE MATERIA PRIMA}

En algún momento entre los pocos años que separan 1827 , fecha de la valorización moderna del corcho lebaniego por los franceses, y 1844, año en el que se produce la primera referencia a una persona dedicada a la fabricación de tapones, aparecen las iniciativas que rebasan las actividades de extracción, preparación y comercio del corcho en bruto para incluir las que implican su trabajo y transformación en productos individuales y definibles. En realidad se puede afirmar que la segundas no sustituyen a las primeras, sino que la combinación de ambas dimensiones, el comercio y la manufactura, es una constante en la actividad corchera de Liébana. Conviene, no obstante, hacer dos precisiones: atrae a un número exiguo de empresarios y como actividad tiene un fin abrupto en 1937 (Cuadro I).

Las noticias sobre el número y características de los talleres son escasas y sucintas a lo largo del siglo xIX, con notables y prolongados vacíos temporales, y algo más ricas en el xx. La información disponible para las primeras centurias muestra una actividad que se mantiene en el tiempo, pero hace difícil observar si existe algún tipo de relación entre Vicente Sierra, Pedro Estanquet, la alusión a una instalación en 1848 o la paternidad de quienes elaboran los tapones que se envían a la exposición de 1857; o, por ejemplo, entre la Sociedad Corchera de 1882 y las referencias a los talleres en 1894 y 1895.

En cualquier caso, los datos obtenidos para el siglo XIX no permiten decir mucho más de estos talleres, aunque casi con toda seguridad les son aplicables las características que los definen en el siglo xx. Así parece mostrarlo la referencia en 1882 a una iniciativa denomi- nada Sociedad Corchera (Llorente, 1882) ${ }^{7}$. Ésta participa en el engalanamiento de Potes con motivo de una visita cinegética de Alfonso XII. Su aportación consiste en el levantamiento de un arco triunfal enteramente confeccionado en corcho, tanto en sus elementos estructurales como en la filigrana decorativa. El dato de interés radica en que se señala que el arco es enteramente tallado por los miembros de la sociedad: el presidente Mariano de Miguel y los consocios Luis Maestro e Isidoro Pantorrilla (Llorente, 1882). Quizá tengan algún empleado más, pero parece que sólo ellos tres constituyen la fuerza laboral más diestra de la empresa.

La pequeña dimensión de los talleres aparece bien retratada en datos posteriores. En 1904, el taller de Potes cuenta con seis empleados y tres el de Castrocillorigo de Liébana; cifras similares, aunque invertidas, a las que se dan en 1915 (seis operarios en Potes y dos en Castrocillorigo) o a las de 1935, cuando se dice que del corcho se viven en Liébana doce familias (Memoria, 1905; ADGB, caja Corcho, legajo 12, 1935b $)^{8}$. Su tamaño se aleja por completo del propio de los talleres artesanos que inicialmente protagonizan y más tarde acompañan en Cataluña a la gran industria en la transformación del corcho (Medir, 1953; Sala, 1998, y Alvarado, 2002). Aunque tienen un bajo nivel de capitalización, al igual que los talleres lebaniegos, el contexto productivo en el que se desenvuelven hace que el número medio de empleados ascienda de 13 en 1845 a 24 en 1900. Por el contrario, la semejanzas ha que buscarlas en los rasgos que definen a otras instalaciones también ubicadas en una posición marginal dentro del mundo corchero español, como son los talleres salmantinos y zamoranos, que con dificultad superan los cinco o seis asalariados.

\footnotetext{
${ }^{7}$ Quizá el nombre de Sociedad Corchera, un tanto ampuloso, tenga que ver con que esta iniciativa funciona en uno de los momentos de oro de esta actividad en España.

${ }^{8}$ Sin duda, esas doce familias incluyen tanto a quienes trabajan en los talleres como a quienes se ocupan de la pela de los alcornoques.
} 


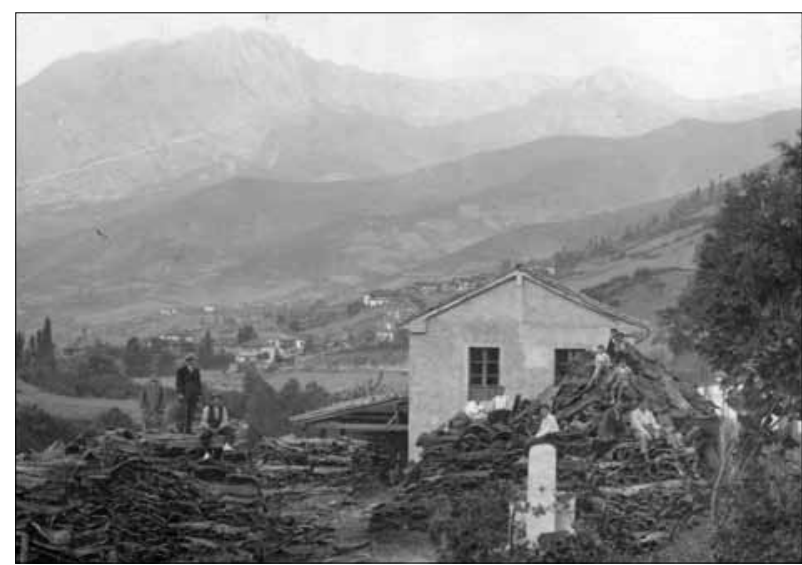

FIg. 3. Instalaciones de La Bienganada, a finales de la década de 1920 (cortesía de la familia Paz).

Los distintos géneros corcheros que elaboran los talleres lebaniegos tienen un destino preferente: el norte de España. La producción de tapones, que en 1913 se cifra en 120.000 unidades, va destinada a abastecer las fábricas de cerveza de Santander y al embotellado de sidra y de frascos farmacéuticos, como reza la presentación de La Bienganada (Memoria, 1905, y ADGB,

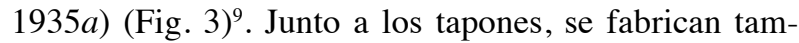
bién algunos géneros menores. Es el caso de flotadores para pesca, principalmente de red, que se venden en los puertos cercanos.

En cuanto al corcho en bruto, parece ser que alimenta a finales del siglo xix y principios del xx un pequeño trasiego comercial protagonizado por carreteros de la montaña central de León. En sus viajes pendulares entre la montaña y el interior de Castilla, se hacen con corcho lebaniego en bruto, lo trabajan toscamente hasta fabricar tapas y tapones y luego los venden en las áreas vinícolas castellanas, por ejemplo Toro (Zamora), de donde vuelven con vino para la montaña. No obstante, este trasiego informal no es más que un matiz. Hacia 1930, parte del corcho lebaniego es enviado a Cataluña. Los lazos comerciales con esta región parece que gozan de buena salud. Antonio Paz, propietario como se ha señalado de La Bienganada, se asocia con Cástor del Río, conocido industrial de Potes poseedor de una fábrica de chocolates y otra de velas, y juntos llegan a acuerdos comerciales con la empresa barcelonesa Gran Serrinera Catalana La Lolita para el suministro de cor-

\footnotetext{
${ }^{9}$ En aquellos años funcionaban las fábricas de cervezas La Cruz Blanca en Santander y La Austriaca en Cajo.
}

cho bornizo y segundero (AHF, D-0199-010, exp. 16). El transporte combina el camión con el ferrocarril. Con el primero se llega hasta Unquera y desde allí se conecta con Barcelona. El problema de esta conexión no estriba en los diferentes anchos de vía, gálibos y diversos empalmes que exige, sino en el complejo y gravoso sistema tarifario que aplican las diferentes compañías a las que hay que recurrir para efectuar el transporte desde el occidente de Cantabria hasta Arenys de Mar. Son estas tarifas precisamente las que en algún momento hacen peligrar la continuidad de los tratos comerciales entre La Bienganada y La Lolita.

La vida de estos talleres, de los cuales La Bienganada de Antonio Paz representa el de mayor envergadura, finaliza abruptamente en 1937 como consecuencia del avance del ejército sublevado contra la Segunda República y el socialismo militante de sus propietarios. El año de 1937 supone así el cierre de un ciclo en el aprovechamiento corchero de Liébana: aquel que combina explotación con transformación protagonizadas por gentes del lugar, por más que en ocasiones emerjan actividades informales de laboreo de esa materia prima (ADGB, caja Corcho, legajo $12,1946 b)^{10}$.

La dimensión de los talleres, su capacidad para producir tapones y sus posibilidades comerciales están condicionadas por el volumen de materia prima que manejan o al que pueden tener acceso. No hay constancia de que su área de abastecimiento no sea otra que la delimitada por los alcornocales lebaniegos y tampoco de que éstos satisfagan de una forma directa las necesidades de otros. De hecho, la documentación señala que los talleres siempre consumen la totalidad del corcho producido en la comarca, la cual oscila, dependiendo del año, entre los 500 y los 800 quintales castellanos; es decir, entre 23 y 36,8 Tm (ADGB, caja Corcho, legajo 12, 1935a). A su vez, la totalidad del suministro proviene de montes concejiles que progresivamente adquieren la condición de utilidad pública. Este rasgo hace que en la disponibilidad de materia prima confluyan los intereses no siempre coincidentes de los propietarios de los alcornocales (entidades locales), administración forestal e industriales. El negocio corcho-taponero remodela las relaciones sociales en torno al alcornoque; construye un nuevo espacio marcado, en no pocas ocasiones, por el conflicto.

\footnotetext{
${ }^{10}$ Los adjudicatarios de una subasta en 1946 piden al Distrito Forestal de Santander que requise una máquina de Ribot a un vecino de Cambarco, quien extrae fraudulentamente corcho de los montes que los primeros tienen asignado.
} 


\section{EL ACCESO A LA MATERIA PRIMA: CON EL TAPÓN LLEGÓ EL CONFLICTO}

Cuando llega a Liébana a través del tapón la valorización industrial y capitalista del alcornoque y del corcho, lo hace sobre un espacio que se arma históricamente con no pocas formas comunales de aprovechamiento del territorio y un complejo sistema de normas que pretenden garantizarlo. En este marco de referencia irrumpe el tapón en un momento que no es neutro. Al contrario, se corresponde con el fin del Antiguo Régimen, con la progresiva instauración en España del Estado moderno y con el nacimiento de una administración forestal, que introduce una nueva racionalidad productiva en los montes con los mecanismos de las subastas y la elaboración de los planes de aprovechamientos forestales (Sanz, 1985).

\section{LA INCORPORACIÓN INICIAL DEL CORCHO A LOS MECANISMOS DE MERCADO}

En Liébana el monte es un espacio de apoyo para la economía campesina, que ocupa la mayor parte del término concejil, siempre de propiedad comunal e interrelacionado con la explotación ganadera (Campos y Lanza, 1985). Los franceses abren el camino en Liébana a la integración industrial del corcho en la producción taponera. La referencia a la presencia de estos comerciantes proviene de fuentes indirectas y, más allá de una alusión genérica a la compra mediante contratos con los pueblos y del buen negocio que representa para los primeros, no hay datos más precisos que permitan esbozar qué tipo de relaciones se establecen entre comunidades rurales, ayuntamientos y compradores. No obstante, parece razonable pensar que si veinte años después otros comerciantes establecen una relación asimétrica en su relación con los pueblos, quizá impere una lógica semejante cuando la presencia francesa en Liébana (hacia 1827-1840) es la única que mercadea con este producto.

En 1847, el pleito de los vecinos de Yebas contra Pedro Irigoyen proporciona suficiente información en este sentido (AHPCA, sección Diputación, serie Montes, legajo 7, núm. 2). El conflicto se establece porque el mencionado Pedro Irigoyen pela setenta y ocho alcornoques sin contar con la autorización del conjunto de los vecinos. En realidad sustituye ésta por una conversación informal con el hermano del alcalde pedáneo, quien le indica «de orden de los vecinos [...] que si quería estraer el corcho, era preciso que abonase alguna cosa, pues de no hacerlo no se le consentía, a lo que contestó aquél [Pedro Irigo- yen] que si el corcho lo merecía les daría alguna cosa como a los de Barreda». Sin todos los detalles cerrados, o sin que el industrial tenga interés en cerrarlos, ya que sobre la licencia para la extracción «ni la tenía ni le hacía falta [pues] en otros pueblos había sacado el corcho sin que nadie se lo impidiese», descorcha los alcornoques y baja el material a Potes. En Barreda, el núcleo que sirve de ejemplo y norma (ciento veinte habían sido los árboles desollados), efectivamente sí que aporta algo a los vecinos. Ante su presión, Irigoyen hace llegar un escrito en el que se compromete «a responder de cuantos perjuicios pudieran sobrevenir», pero que en realidad no supone un contrato entre el propietario del monte y quien quiere aprovecharlo. El vecindario de Barreda accede «aunque de mala gana, en virtud de la obligación que les había hecho, y por evitarle perjuicios», concluyendo el negocio con que el vecino de Potes, sin que haya petición previa (es decir, sin que se pueda entender como la obligación asumida dentro de un contrato comercial), invita al vecindario a un convite y les proporciona veinte reales de gratificación (AHPCA, sección Diputación, serie Montes, legajo 7 , núm. 2).

El texto retrata una integración mercantil del corcho que posee coordenadas propias. La dimensión comunal del descorche no reside en quienes protagonizan el aprovechamiento, sino en que, aunque sea realizado por un tercero, la comunidad en su conjunto decida si se ha de efectuar y qué tipo de retorno debe recibir. Para que esto último sea justo parece necesario que el propietario del derecho, en este caso el común de los vecinos, conozca el valor de mercado del corcho que producen sus montes. Sin embargo, este conocimiento no se posee y tampoco el comprador está interesado en transmitirlo, una asimetría de la que este último saca un notable rendimiento (AHPCA, sección Diputación, serie Montes, legajo 7, núm. 2).

No obstante, el desequilibrio en esa relación parece que se corrige con el tiempo. El rastro de Pedro Irigoyen vuelve a aparecer, junto con el de Vicente Sierra, en $1851^{11}$. Ambos aprovechan en sociedad alcornocales en Potes, Camaleño y Cabezón de Liébana, si bien el conflicto no se plantea con los concejos. De hecho, no se recoge en la documentación ninguna queja de éstos, toda vez que se señala la existencia de contratos con los ayuntamientos y se reconoce que «han sido útiles y convenientes para los pueblos, mejorando sus bosques y dando

\footnotetext{
11 Vicente de la Sierra es sin duda «el joven Sierra» al que se refiere la memoria de 1840 de La Económica como el primer lugareño que se dedica al trasiego de corcho después de la desaparición de los franceses.
} 
rendimientos que de otro modo no hubieran tenido en sus fondos» (AHPCA, sección Diputación, serie Montes, legajo 7 , núm. 2). Puede que de alguna forma el juego ventajoso del corchero se mantenga, pero la propia existencia de esta documentación anticipa la entrada en escena de la administración como actor, aunque inicialmente de una forma tímida, ya que sólo añade un barniz administrativo al procedimiento del aprovechamiento del corcho pero sin invalidarlo o cuestionarlo en su fundamento. En pocos años esta laxitud sólo es un recuerdo y el conflicto, la tensión, ya no tiene al corchero como parte directamente interesada, sino que se entabla entre los pueblos con monte alcornocal y la administración forestal.

\section{El MECANiSMO DE LAS SUBAStaS COMO FUENTE DE TENSIÓN}

La moderna administración forestal española se construye en un lento proceso que se inicia en 1833 con la promulgación de las ordenanzas de Montes y que ocupa gran parte del siglo XIX (Gómez, 1992, y Casals, 1996). Éste conlleva la progresiva descomunalización del monte, a la que contribuyen decisivamente la ley de Montes de 1863 y su posterior desarrollo reglamentario en 1865. En su artículo 94 establece que «todo aprovechamiento de productos forestales se adjudicará precisamente en subasta pública». Este principio genérico tiene algunas excepciones, pero ninguna de ellas resulta en la práctica aplicable al corcho.

La cantidad de corcho que se subasta es la que recogen los planes anuales de aprovechamientos forestales y el documento que la lleva a la práctica lo constituye el pliego de condiciones técnicas. En el articulado de estos pliegos aparecen regulados, además del precio base de puja, todos los aspectos que velan por la integridad forestal del monte y pecuniaria del erario público y que otorgan garantía jurídica en el aprovechamiento al pueblo propietario y al adjudicatario del remate. A pesar de su exhaustividad, no evitan la posibilidad de su interpretación, sobre todo en aquellas condiciones que exigen confrontar cómo discurre en realidad el aprovechamiento del corcho con la literalidad del pliego que lo regula.

No son infrecuentes disputas de carácter menor relacionadas con daños en el arbolado o con ligeras discrepancias en la interpretación de los pliegos, pero también aparecen otras que, si sirve de evidencia la documentación que generan, poseen un mayor calado. En las segundas hay un motivo recurrente: extracciones de corcho que los pueblos consideran abusivas y dañinas para los erarios locales y los rematantes ajustadas en todo término a las condiciones estipuladas en cada pliego. En 1883, los alcaldes pedáneos de las localidades de Frama y Cambarco (Cabezón de Liébana) promueven una reclamación sobre el aprovechamiento de los montes Cornejas, Ampudia y Reocín que un año después llega al Consejo de Estado (AMA, Fondo Montes siglo XIX, caja 395-B, exp. 11). En el plan de aprovechamientos del año forestal de 1881 a 1882 se consignan ochenta quintales métricos de corcho repartidos entre los tres montes y tasados en seiscientas pesetas (7,5 pesetas por quintal). El pliego establece en su condición quinta que «el descorche ha de verificarse en toda la extensión de los montes, respetándose todos los árboles que sean menores de sesenta centímetros de circunferencia o cuyo corcho no pase de cuatro de grueso». Los alcaldes, una vez adjudicada la subasta y comenzado el aprovechamiento, piden al gobernador civil de Santander que lo suspenda toda vez que el rematante extrae del monte una cantidad de corcho notablemente superior a la fijada en el pliego, lo que supone infringir las condiciones que rigen la subasta ${ }^{12}$. El aludido argumenta, por el contrario, en una doble dirección. Por un lado, se defiende señalando que el pliego de condiciones indica que el contrato se realiza a ventura y riesgo y que la cláusula quinta le proporciona «el derecho al aprovechamiento de todos los árboles del monte no excluidos de la misma condición». Por otro, apela a la racionalidad mercantil y económica. El remate final, su puja, alcanza las 2.030 pesetas; es decir, 25,37 pesetas por cada uno de los ochenta quintales que sirven de base a la subasta, cuando para quien «conociera medianamente la industria corchera [...] dicho producto no alcanza ni con mucho semejante precio en el mercado». Por ello, se debe entender que

[...] el número de quintales métricos que figuran en el pliego de condiciones no tiene más carácter que el de un cálculo o tipo para la subasta, y que el aprovechamiento debe entenderse de todo el corcho que produzcan los montes, sin más limitaciones que las designadas en la condición quinta del pliego, según se había venido siempre haciendo en las subastas celebradas en los pueblos del distrito de Cabezón de Liébana, sin que en los de Cambarco y Frama se hayan opuesto o reparo a ello. (AMA, Fondo Montes siglo XIX, caja 395-b, exp. 11)

El gobernador civil atiende en primera instancia a lo solicitado por los pueblos, pero poco después le proporciona la razón al rematante como consecuencia de su

\footnotetext{
${ }_{12}$ El adjudicatario de la subasta es un vecino del cercano pueblo de Ojedo llamado Nicolás Lamadrid, sin vinculación aparente con la Sociedad Corchera, en funcionamiento en esos años, aunque quizá le suministrase materia prima.
} 
reclamación y del informe que emite el ingeniero jefe del Distrito Forestal de Santander. La posición de éste se sitúa aparentemente del lado del industrial corchero al informar de que «en el disfrute del corcho no se había faltado a ninguna de las condiciones del pliego que rigió la subasta», achacando el malentendido a «un error en el contrato de compraventa y no pudiendo dudarse de la buena fe de ambas partes contratantes». En términos parecidos se manifiesta, reforzando los argumentos expuestos por el ingeniero jefe del Distrito Forestal de Santander, la Junta Facultativa de Montes:

[...] lamenta que la aparente contradicción que parece existir entre el encabezamiento del pliego de condiciones que rigió la subasta y la condición quinta del mismo, haya sido objeto de cuestión, cuando la práctica constante en estos mismos pueblos tenía ya resuelto el problema en el sentido que en dicha condición quinta se indica [...], puesto que es sabido que la cantidad de quintales métricos fijada en el encabezamiento del pliego de condiciones, sólo se ha consignado siempre como tipo para la subasta, y que el rematante tenía perfecto derecho a la cantidad existente en los tres montes que se subastó, con las limitaciones marcadas en la misma condición.

No obstante, la cuestión no parece tan transparente como enuncia la Junta; y no porque ésta se vea obligada a admitir el recurso presentado por los alcaldes pedáneos debido a un defecto en la tramitación del expediente por parte del gobernador civil de Santander, sino porque el Consejo de Estado declara nulo el 31 de octubre de 1884 el acuerdo a favor del rematante con argumentos rotundos:

[...] se trata de fijar la inteligencia o interpretación de un contrato administrativo que afecta en primer término a los intereses de los pueblos expresados, para quienes no puede ser indiferente que el contratista del aprovechamiento de sus montes extraiga de ellos todo el corcho que produzcan, o tan sólo los ochenta quintales métricos de que se hizo mérito el anuncio de subasta. (AMA, Fondo Montes siglo XIX, caja 395-b, exp. 11) ${ }^{13}$

En general, la administración forestal se muestra, en el caso del corcho, refractaria a los intereses de los pueblos y más cercana a las posiciones del rematante de las subastas. Esto, que es perfectamente observable en la documentación de 1882, vuelve a asomar unas décadas después, aunque en este caso la disputa aparece envuelta en una densa maraña de intereses que, desplegada tanto por la administración como por las juntas vecinales, exceden lo silvícola para adentrarse, aunque no todos los argu-

${ }^{13}$ La Junta Consultiva de Montes estima que la segunda resolución del gobernador civil de Santander que atiende los argumentos del rematante es nula de pleno derecho, pues la primera, favorable a los intereses de los pueblos, sólo puede ser enmendada recurriendo al proceso contencioso administrativo. mentos se hacen explícitos, en la dimensión crematística que tiene el negocio corchero.

Con el objeto de hacer más interesante comercialmente la extracción de corcho y superar las limitaciones productivas de cada monte particular, la administración forestal subasta a finales de los años cuarenta del siglo xx la producción de todos los alcornocales de Liébana por un periodo de catorce años (entre los años forestales de 1946-1947 y 1956-1960) (ADGB, caja Corcho, legajo 12, 1946a). La subasta, que saca a puja el aprovechamiento de 4.200 Qm, se celebra en octubre de 1946, pero es anulada por las irregularidades que se cometen y las reclamaciones que presentan las juntas vecinales de Frama, Cambarco y Cahecho y el Ayuntamiento de Potes. Las irregularidades estriban en el hecho de no admitirse la postura presentada con la suficiente antelación por el representante en Santander de una de las principales compañías corcheras catalanas, Esteva \& Messer, y a que entre la fecha de publicación del anuncio en el Boletín Oficial de la provincia (14 de octubre) y la celebración de la subasta ( 25 de octubre) no hay un mínimo de veinte días de separación, tal y como la legislación establece. Ausencia de publicidad y criterios restrictivos en la presentación de plicas (limitación de la concurrencia al fin y al cabo) dan lugar a que inicialmente se adjudique la subasta al único postor que se admite: el vecino de Cabezón de Liébana Segundo Santervás Uribe. Éste, con una puja de 31.600 pesetas, sólo mejora en cien la cantidad consignada como de salida: 31.500 pesetas (ADGB, caja Corcho, legajo 12, 1946b). La subasta se repite un poco después, el 17 de diciembre de 1946. En este caso, los que licitan son el representante de Esteva \& Messer con 44.100 pesetas, el de la corchera coruñesa La Galaica con $87.405,5$ pesetas, quien resulta beneficiario del aprovechamiento, y Ciriaco Fombellida Lledia, del cercano pueblo de Ojedo, con una sorprendente puja que no es considerada: 25,95 pesetas más que el que más dé.

Estos avatares previos no hacen sino anticipar las dificultades y tensiones con las que se va a encontrar el aprovechamiento de corcho a lo largo del tiempo consignado en la subasta. Se suceden varias reclamaciones por aprovechamientos abusivos que dan lugar a denuncias judiciales por hurto contra el rematante y a una intensa discusión en los últimos años del período subastado con el objetivo de revisar al alza del precio a pagar por quintal métrico extraído. Algunas de las causas de esta turbulencia tienen sus raíces en un aspecto que parece constituir una invariante (cómo entender los tipos de licitación de las subastas y la modalidad de los contratos que se firman una vez realizadas éstas) y otras en los intereses que des- 
piertan los ingresos de un negocio del que los lebaniegos desaparecen en 1937.

El rematante contrata esos 4.200 Qm en catorce años por $87.405,5$ pesetas, lo que da un valor unitario de 20,81 pesetas por quintal. Para el contratista y la administración forestal la cantidad extraíble establecida en el pliego de condiciones sólo sirve para fijar el tipo base de la licitación (los aforos están basados en la experiencia y no hay ningún cálculo sobre las calidades del corcho), prevaleciendo el hecho de que los contratos se firman a «riesgo y ventura» (ADGB, caja Corcho, legajo 12, 1959a). Por el contrario, para las juntas vecinales el tipo base de licitación implica por necesidad un límite a la extracción que no se puede superar (argumento también idéntico al de sesenta años antes) o, si lo hace, debe ser abonando a mayores el precio por quintal métrico que se obtiene de dividir el aprovechamiento por la puja en la que se remató la subasta. Lo contrario es un quebranto inadmisible para las arcas de las juntas vecinales.

El rematante considera igual de inasumible este planteamiento y ello va a llevar a que sea denunciado en 1952 y 1958 por hurto ante el Juzgado de Potes, primero por el aprovechamiento del monte de Cambarco y después por el de Frama (ADGB, diversos documentos, caja Corcho, legajo 12,1958b). Ante la gravedad de los hechos, la junta vecinal de Frama envía un escrito al gobernador civil en el que hace un relato pormenorizado del origen de la discordia (ADGB, caja Corcho, legajo 12, 1958a). En ella señala que «la junta vecinal estimó que si el adjudicatario descortezaba todos los alcornoques del citado monte [el de Hinojeda], habría de extraer una cantidad muy superior a los $30.000 \mathrm{~kg}$ a los que tenía derecho». Una vez concluido el descortezamiento «depositó [el rematante] todo lo extraído en una tierra cercana a Puente Vieda y ascendía a $70.000 \mathrm{~kg}$ aproximadamente, es decir unos $40.000 \mathrm{~kg}$ más de los que había abonado y que estimábamos que tenía derecho causando un grave perjuicio a los intereses de esta Junta». En su reunión del 18 de diciembre de 1958, requiere del adjudicatario que cese en el transporte de corcho a la estación de Torrelavega una vez que se rebasan los $30.000 \mathrm{~kg}$ iniciales. El requerimiento no es acatado y «acto seguido se requirió el auxilio de la Guarda Civil del puesto de Potes y una vez personada la misma se paralizaron los trabajos no habiéndose extraído más corcho, digo levantado más corcho desde ese momento» (ADGB, caja Corcho, legajo 12, 1958a) ${ }^{14}$. El

\footnotetext{
${ }^{14} \mathrm{La}$ junta vecinal argumenta, por otro lado, que los ingresos del corcho son los únicos de los que dispone y ante «las grandes y apremiantes necesida-
}

razonamiento por tanto es que los cuatrocientos quintales métricos extraídos por encima de los trescientos anuales consignados en el pliego son «bienes patrimoniales de esta junta pudiendo importar la citada cantidad una suma aproximada a las $200.000 \mathrm{pts} . »$.

A este motivo recurrente de fricción se le añada otro que, por distinta vía, incide en el mismo argumento del quebranto de las arcas de las juntas vecinales: es el de la revisión del precio del corcho. La cláusula sexta del pliego de condiciones de la subasta prevé que el precio pagado se puede modificar si en el transcurso de los catorce años de aprovechamiento experimenta una elevación o depreciación superior al veinte por ciento sobre el fijado en el remate, correspondiendo a la jefatura de montes señalar el nuevo precio para los años siguientes. En 1957 la junta vecinal de Frama solicita que se revise al alza el precio por quintal métrico que el rematante abona. Antes de profundizar más en este nuevo litigio y en sus implicaciones es necesario hacer otras consideraciones, introducir nuevos intereses y actores. El resultado final de la puja de 1946 supone la consolidación de la ausencia de los capitales lebaniegos en el negocio del corcho desde 1937, desplazándose por completo el valor añadido que genera su mercadeo o transformación a otras regiones españolas. Algunas personas, por lo que aflora en la escasa documentación conservada, despliegan una intensa actividad. Es el caso de Nicanor Fombellida, postor en 1946. Nueve años más tarde envía una carta manuscrita al ingeniero de montes de Santander en la que, arropándose con el discurso de la defensa de los intereses de los pueblos, se evidencia que sigue con detenimiento la evolución de las operaciones y los trabajos efectuados por el adjudicatario del remate. Incluso se puede llegar a pensar que es tanto el empeño que pone que no sería extraño que sus reflexiones alimenten y den munición a las quejas de las juntas vecinales.

Nicanor Fombellida le recuerda al ingeniero de montes «que en el mes de octubre fue puesto en conocimiento de Ud. los abusos que viene cometiendo el rematante de corchos, en esta zona de Liébana, sin que todavía se haya hecho cumplir, si no enteramente, en parte el pliego

\footnotetext{
des de este pueblo, los vecinos del mismo ven con gran satisfacción la energía y el interés demostrado en la defensa de sus derechos, y verán quizá hecha una realidad el arreglo del puente que si bien se encuentra en el Plan de Cooperación Provincial no es en cantidad suficiente para realizar en el mismo las obras apetecidas y necesarias, así como una traída de agua en el mismo, que sueño en algún momento, hoy se vislumbra como posible realidad de salir airosos en nuestra empresa, como esperamos» (ADGB, caja Corcho, legajo 12, 1958a). El mensaje por otro lado esté claro. El dinero obtenido puede servir para culminar obras planteadas por el Estado.
} 
de condiciones de dicha subasta. Incumplimiento que le ha costado a los pueblos sumas importantes de dinero» (ADGB, caja Corcho, legajo 12, 1955). Se refiere el denunciante a un escrito que se recibe en Santander a través de la alcaldía de Potes y en el que Nicanor Fombellida, junto con cuatro personas más, traslada algunas irregularidades que se están produciendo: rebasar la altura de descorche (lo que permite conseguir más corcho del que estima que está autorizado el rematante), no revisar al alza los precios (se señala que el corcho ha llegado a valer 15 pesetas por kilo en otros mercados) y, por último, no limpiar el monte como era preciso. La documentación no permite saber cuál es la respuesta oficial a esta denuncia y, aunque algún asunto como el de la revisión no concierne al rematante, todos sí que son responsabilidad en mayor o menor medida del distrito forestal. Lo cierto es que dos años después se produce la petición de revisión de los precios que hace la junta vecinal de Frama.

Los vecinos utilizan como referencia para su solicitud el valor que alcanza el corcho en las subastas que entre 1951 y 1954 se celebran en el pueblo malagueño de Caucín. En estos años, el del quintal métrico del corcho hembra o segundero oscila entre las 12 y las 451 pesetas, mientras que el bornizo lo hace entre las 63 y las 100 pesetas. El distrito forestal asume la necesidad de revisar al alza el precio del corcho, pero no hace suyos los números aportados por la junta vecinal; no porque sean inciertos, sino por no ser válidos para la realidad del corcho lebaniego. El ingeniero, no sin antes recabar información directa del precio del corcho en Málaga tanto en monte como ya cocido, raspado y enfardado, argumenta en el siguiente sentido:

Estos precios son aceptables en zonas que, como Andalucía, producen una gran cantidad de corcho y puede compensar al rematante pagar esos precios, a parte de existir zonas de consumo mucho más próximas, y por tanto ser menor el coste de transporte; hay que tener en cuenta, además, que la calidad del corcho de Liébana es notoriamente inferior al de Andalucía y, por tanto, no debe equipararse en ningún momento al de esta zona; en resumen y para tratar de evitar, dadas las razones expuestas, que en lo sucesivo el aprovechamiento de corcho en Liébana se quede sin rematantes, deberá establecerse un precio asequible, tal que les interese a los rematantes (al menos los norteños) de este aprovechamiento. (ADGB, caja Corcho, legajo 12, 1958b) ${ }^{15}$.

\footnotetext{
${ }^{15}$ Más de un siglo después de iniciado el uso industrial del corcho en Liébana, este pequeño párrafo quizá sea la valoración más acertada del potencial corchero de la comarca. Por otro lado, los datos que se reciben desde Málaga señalan que es difícil señalar un precio único para el corcho, ya que éste se divide en cinco calidades que a su vez se subdividen en otras cinco. Haciendo abstracción de este condicionante, el precio medio en monte es de 350 a 400 pesetas para el corcho segundero y de 100 para el bornizo. A pesar de la varia-
}

El ingeniero en su propuesta final rebaja considerablemente las pretensiones de la junta vecinal de Frama. En concreto, estima que se debe establecer una quita de un $35 \%$, un $60 \%$ y un $75 \%$ sobre el valor que en Andalucía tiene el corcho segundero, el hembra y el bornizo respectivamente, y con estos nuevos valores, dado que no hay capacidad para controlar las calidades del corcho, obtener un valor medio que sirva de precio en los años finales del remate. Ese precio es de 122,97 pts./Qm, casi seis veces superior al que tiene cuando se adjudica la subasta en 1946 (ADGB, caja Corcho, legajo 12, 1958b).

$\mathrm{El}$ rematante no desiste del aprovechamiento. Asume el nuevo precio, si bien con la salvedad de que «la aceptación comprende única y exclusivamente los trescientos quintales métricos amparados por la adjudicación y de conformidad con lo dispuesto en la condición 16 del pliego de condiciones» (ADGB, caja Corcho, legajo 12, $1958 b)$. La aceptación del precio no le garantiza al rematante una cierta tranquilidad en el aprovechamiento del corcho. Al contrario, es un argumento para que los problemas aumenten. Al ya descrito pleito con la junta vecinal de Frama en 1958 se le añaden nuevos frentes; en concreto con el Ayuntamiento de Potes, que le impide en 1959 sacar el corcho de las campañas de 1955-1956 y 1956-1957 al entender que a éstas se les debe aplicar también el precio vigente a partir de la campaña de 19571958. Este litigio tarda en resolverse, pero no impide que La Galaica, una vez terminado el contrato de los catorce años, siga pujando y obteniendo subastas de corcho en Liébana.

\section{LA PRODUCCIÓN DE CORCHO, EL ESTADO DE LOS ALCORNOCALES Y LOS RASGOS DE LA SILVICULTURA CORCHERA}

\section{LOS RITMOS EN LA PRODUCCIÓN DE CORCHO}

A pesar de ser un espacio perfectamente acotado y de provenir toda la materia prima de montes públicos y de utilidad pública, resulta difícil reconstruir la producción histórica de corcho en Liébana. Es de sobra conocido cómo, a las deficiencias que presentan las estadísticas

ción que existe en el mercado, el informante apunta que el precio del segundero se sitúa entre las 1.400 y 3.300 pesetas el quintal métrico y unas 500 pesetas el bornizo. Para el cálculo del beneficio hay que restar el coste de descorche, unas 24 pesetas por quintal métrico, y el de transporte ( $\mathrm{ADGB}$, caja Corcho, legajo 12, 1957). Estas cifras ayudan a entender los márgenes en los que se desenvuelve el negocio del producto. 
CuAdro II. Producción quinquenal de corcho en Liébana (1850-2009)

\begin{tabular}{|c|c|c|c|}
\hline Quinquenio & $\begin{array}{l}\text { Serie 1. Producción } \\
\text { quinquenal según las } \\
\text { estadísticas (en Tm) }\end{array}$ & $\begin{array}{l}\text { Serie 2. Producción } \\
\text { quinquenal corregida con } \\
\text { la documentación (en Tm) }\end{array}$ & $\begin{array}{c}\text { Variación } \\
(\text { Serie } 2-\text { Serie } 1)(\text { en Tm) }\end{array}$ \\
\hline $1850-54$ & 0 & 5,52 & 5,52 \\
\hline $1855-59$ & 0 & 0 & 0 \\
\hline $1860-64$ & 0 & 0 & 0 \\
\hline $1865-69$ & 0 & 0 & 0 \\
\hline $1870-74$ & 0 & 0 & 0 \\
\hline $1875-79$ & 3,02 & 3,02 & 0 \\
\hline $1880-84$ & 9,4 & 20,02 & 10,62 \\
\hline $1885-89$ & 7,7 & 7,7 & 0 \\
\hline 1890-94 & 0 & 5 & 5 \\
\hline 1895-99 & 0 & 1 & 1 \\
\hline 1900-04 & 0 & 0 & 0 \\
\hline 1905-09 & 10 & 30 & 20 \\
\hline 1910-14 & 0,004 & 4,004 & 4 \\
\hline 1915-19 & 0 & 2 & 2 \\
\hline $1920-24$ & 0 & 0 & 0 \\
\hline $1925-29$ & 0,32 & 21,756 & 21,4 \\
\hline $1930-34$ & 6,72 & 9,66 & 2,94 \\
\hline 1935-39 & 0 & 18,02 & 18,02 \\
\hline $1940-44$ & 7,2 & 7,2 & 0 \\
\hline $1945-49$ & 28 & 59 & 31 \\
\hline $1950-54$ & 24 & 24 & 0 \\
\hline $1955-59$ & 25,8 & 51,2 & 25,4 \\
\hline $1960-64$ & 88,56 & 88,56 & 0 \\
\hline 1965-69 & 45,56 & 45,56 & 0 \\
\hline $1970-74$ & 141,18 & 190,7 & 49,52 \\
\hline $1975-79$ & 0 & 47,78 & 47,78 \\
\hline $1980-84$ & 0 & 84,084 & 84,08 \\
\hline $1985-89$ & 0 & 18,8 & 18,08 \\
\hline $1990-94$ & 86,32 & 86,32 & 0 \\
\hline 1995-99 & 0 & 0 & 0 \\
\hline 2000-04 & 0 & 61,38 & 61,38 \\
\hline 2005-09 & 1 & 1 & 0 \\
\hline
\end{tabular}

Fuente: Serie 1, Planes de aprovechamientos forestales (1877-1909); Estadísticas de producción de los montes públicos (1911-1931); Anuario estadístico de España (1933 y 1972-2000); Estadística forestal de España (1946-1971) y Anuario de estadística forestal (2005-2010). Serie 2, Archivo de la Dirección General de Biodiversidad del Gobierno de Cantabria.

forestales españolas, se le suman otras dificultades exclusivas del corcho (Jiménez, 1999). Esta últimas tienen que ver, principalmente, con el hecho de que bajo la denominación de «cortezas» se computan en ocasiones algunas que no son corchos, con la indefinición de las unidades de medida que se utilizan y con la circunstan- cia de que la cantidad consignada en las estadísticas se corresponde en no pocas ocasiones con los aprovechamientos previstos, pero no necesariamente con los realmente obtenidos. Éstas y otras dificultades están presentes en las cifras de producción que se proponen para los alcornocales de Liébana. Si bien existe algún dato previo 
que proviene de los informes de los visitadores de montes y plantíos (1851), el grueso de la información tiene su origen en los planes de aprovechamientos forestales (1877-1909), en las Estadísticas de producción de los montes públicos (1911-1931), en el Anuario estadístico de España (1933 y 1972-2000), en la Estadística forestal de España (1946-1971) y en el Anuario de estadística forestal (2005-2010).

Toda esta información adquiere su significado pleno cuando se confronta con la que, en el contexto de la administración forestal, genera el servicio diario de estos montes. Su valor radica en que ayuda a cubrir huecos en las estadísticas oficiales que no se deben a la ausencia de extracciones de corcho sino a una ineficiencia en su confección, y, sobre todo, en que se corrige, normalmente al alza, las cifras de la oferta anual de materia prima de los alcornocales lebaniegos. Las estadísticas oficiales lo que reflejan en no pocas ocasiones (por ejemplo entre 1947 y 1960) es el número de quintales métricos que sirven para fijar el precio base de las subastas, pero no la cantidad realmente extraída, más cuando el pliego establece que el aprovechamiento es a riesgo y ventura. En estos casos, las cifras reales suelen ser más abultadas que las oficiales, aunque no faltan momentos en los que parones vegetativos veraniegos e incendios las modifican en sentido contrario. La cantidad extraída se presenta en medias quinquenales, aun sabiendo que la variabilidad anual es, dadas las características silvícolas de los alcornocales lebaniegos y el lugar donde se ubican, su principal características productora.

Se ha preferido, no obstante, construir dos series quinquenales (Cuadro II). La primera sólo con los datos reflejados en las estadísticas oficiales y la segunda con éstas corregidas, allí donde es posible, con la cifra máxima que para cada periodo de tiempo aparece en la documentación forestal. Ambas líneas poseen un perfil semejante, aunque es la segunda la que permite reconocer con más nitidez distintas fases en la oferta de corcho de los montes públicos lebaniegos. Se pueden distinguir, a grandes rasgos, tres grandes «metaciclos», de duración desigual, que engloban otros ya descritos para el conjunto de la producción corchera española (Jiménez, 1999). El primero, que se prolonga desde las últimas décadas del siglo XIX hasta 1940, es sin duda es el periodo más genuino en la historia de la producción corchera de Liébana; el único en el que la materia prima de la comarca sirve para alimentar a los pequeños talleres taponeros de Potes y Puente Ojedo y, por tanto, el único también en el que el ciclo transformador al que da lugar el corcho está protagonizado en su totalidad por agentes locales.
El hecho de que la serie anual tenga extensos vacíos dificulta realizar un análisis más preciso que el que se ofrece. No obstante, el que algunos de aquéllos se deban a subastas que quedan desiertas hace que la falta de datos proporcione en sí misma una valiosa información. En general, lo que se observa son unas producciones anuales que, aunque rebasan las $50 \mathrm{Tm}$ en su valor máximo, rara vez se mantienen en esta magnitud el tiempo suficiente como para propiciar medias quinquenales significativas. De hecho, la producción de corcho es baja, incluso cuando la aparición del aglomerado comience a proporcionar valor industrial y comercial al bornizo. Las cesuras que en este periodo posee la serie puede que se deban, además de a la insuficiencia en las fuentes, a la propia realidad del medio productor, y al reflejo que en Liébana tienen las propias dinámicas del negocio corchero español. Sirva como ejemplo la disminución en la oferta de materia prima en los montes públicos españoles que se produce a partir de 1914 y que se extiende hasta 1925 coincidiendo con la fuerte retracción en la demanda mundial de corcho que conlleva la primera guerra mundial y su no recuperación hasta el segundo lustro de la década de los veinte (Jiménez, 1999). Precisamente, la documentación del antiguo distrito forestal de Santander muestra cómo en este periodo de tiempo (1914 y 1915, aunque lo mismo ocurre en 1913) las subastas quedan desiertas ante la ausencia de licitadores, si bien no es posible indicar hasta cuando se mantiene esta situación. En cualquier caso, la producción recupera los valores que la caracterizan antes de la crisis de 1914 a partir, aproximadamente, de 1925, al igual que ocurre en el resto del espacio productor de corcho. No obstante, si en el conjunto español la recuperación en las extracciones hace que éstas se eleven hasta unos límites desconocidos hasta ese momento como consecuencia del aumento de precios del corcho y de las nuevas utilidades industriales que se le proporciona (Medir, 1953; Zapata, 1996, y Jiménez, 1999), aparentemente no ocurre lo mismo en Liébana. En estos años se extraen cantidades de corcho significativamente superiores a las anteriores a 1914, como lo muestra la venta en 1929 de $120 \mathrm{Tm}$ de corcho bornizo con destino a la industria catalana del aglomerado (AHF, D-0199-010, exp. 16) ${ }^{16}$.

La guerra civil interrumpe los descorches hasta 1938. En ese año son retomados, aunque el aprovechamiento recae a partir de esa fecha en foráneos. El empeño que la administración forestal pone por regularizar y aumentar

\footnotetext{
${ }^{16}$ Cabe preguntarse si esta cantidad es resultado de la pela de un año o de la liberación de existencias acumuladas durante un tiempo más largo.
} 
las producciones, quizá también como una forma de propiciar una licitación más concurrida a las subastas, junto con, paradójicamente, una cierta laxitud (opuesta al principio de la regularización) en el seguimiento de los aprovechamientos adjudicados, hacen que aumente de una forma considerable, muy por encima de las cifras precedentes, la cantidad de corcho extraído en los montes de Liébana.

Esta dinámica se interrumpe con el cambio de siglo y continúa hasta la actualidad. Algunos incendios, las restricciones ambientales que la mirada patrimonial proyecta sobre todos los montes de la comarca y el limitado interés comercial que despierta en la actualidad el corcho lebaniego hacen que su aprovechamiento se haya convertido en un evento excepcional.

\section{LOS PROBLEMAS DEL ARBOLADO Y EL ESTADO SILVÍCOLA DE LAS MASAS DE ALCORNOQUE}

Desde los comienzos de la actividad corchera, o desde que los registros documentales sobre ella comienzan a ser abundantes, no son infrecuentes las alusiones a las deficiencias que presenta el arbolado para la producción de corcho taponable, bien por las características con las que los alcornocales llegan a los momentos centrales del siglo XIX, bien por los daños que sufre al convivir el aprovechamiento corcho-taponero con otros esquilmos o bien por la frecuencia con la que las operaciones de descorche son mal ejecutadas. En ese mal estado radica, como se ha señalado, el origen de la propuesta del bosque modelo que la Sociedad Económica de Amigos del País de Liébana hace en 1840, a la vez que la petición de limpiar y acotar al pasto una parte de los montes de encina y alcornoque. La relación de montes de la provincia de Santander señala en 1847 para los del ayuntamiento de Potes que «la mayor parte son árboles nuevos, por haberse puesto algún cuidado en estos montes y en particular en el de Tolibes, que casi todo es de alcornoque, de algunos años a esta parte» (AHPCA, sección Montes, legajo 16) ${ }^{17}$. Parece por tanto que las propuestas de La Económica son bien acogidas, tanto en lo referente a la limpieza de los montes como, aunque aquí sólo cabe la conjetura, al establecimiento del bosque modelo. El pago que la sociedad propone para ese fin es del Camarinas, en el monte de Tolibes, y aparentemente es a éste al que se presta una mayor atención. No obstante, no parece que

\footnotetext{
${ }^{17}$ Queda fuera de los objetivos de este trabajo, pero podría ser de interés estudiar las implicaciones geobotánicas de la explotación corchera en Liébana.
}

estos trabajos culturales se caractericen por su continuidad. Los informes elaborados por el personal de montes a lo largo de la segunda mitad del XIX y buena parte del $\mathrm{xx}$ inciden en este hecho, al igual que los relatos que incluyen noticias sobre la industria corchera y los alcornocales. La publicación de 1913 Liébana y los Picos de Europa contiene un retrato poco halagüeño: «[...] los montes más importantes de alcornoque se encuentran en el término municipal de Cabezón de Liébana y en el de Potes; sin embargo, bastante abandonada su administración y su explotación, no rinden el producto de corcho de que serían susceptibles y es de temer que poco a poco vayan desapareciendo» (LVL, 1913, p. 26). Dos décadas después, una pequeña memoria de 1932 sobre los alcornocales y el corcho que el sobreguarda de Liébana envía al ingeniero de montes encargado de esta comarca describe el estado de los montes al finalizar el primer tercio del siglo XX (ADGB, caja Corcho, legajo 12, 1932). Se señala de todos ellos que necesitan «una imperiosa necesidad de grandes limpias y entresacas». Aparecen los alcornocales mezclados con encinas, robles, madroños y otros arbustos que deben desaparecer «para prosperidad del corcho [y] para evitar riesgo de incendio» ${ }^{18}$.

Por otro lado, el alcornocal no llega virgen al momento en el que el paradigma de su explotación comienza a girar en torno al tapón. Antes de que éste se despliegue, el monte satisface necesidades para las cuales una determinada edad, forma o estructura del arbolado no son rasgos silvícolas que deban estar necesariamente orientados en un determinado sentido. Esto hace que la presencia en ocasiones importante de grandes y añosos alcornoques sea vista por el gestor como un problema. Es lo que ocurre, por ejemplo, en la dehesa de Lubayo, en la localidad de Frama. En ella «los árboles [son] viejos y el corcho inaprovechable» (ADGB, caja Corcho, legajo 12, 1915); o lo que también sucede en Perrozo, donde los árboles, «aunque fueron subastados [...], no se desbornizaron por ser viejos y de difícil pela» (ADGB, caja Corcho, legajo 12, 1938).

\section{EL DESORDEN EN LOS APROVECHAMIENTOS Y LAS EXPERIENCIAS INCOMPLETAS DE ORDENACIÓN}

No es, sin embargo, en la vejez de parte del arbolado donde hay que buscar los condicionantes que con

\footnotetext{
${ }_{18}$ El relato del sobreguarda expone un problema que rebasa una fecha y un espacio concreto. La intensa regeneración del matorral y la fuerte competencia que esto supone dificulta la producción de corcho en todos los alcornocales de monte.
} 
más intensidad limitan el desarrollo de las posibilidades productoras de corcho. Sin duda, el fundamental es que no llega a ponerse en marcha una auténtica silvicultura corchera, a pesar de los intentos y de que todo el espacio productor adquiere la condición de monte de utilidad pública, sujeto a la tutela de la administración forestal $\mathrm{y}$, por tanto, bajo el principio de la búsqueda de la persistencia del arbolado y el rendimiento sostenido de la producciones. En el tiempo se suceden dos procesos: uno que persigue una regularización de los aprovechamientos y otro que busca una ordenación, en su sentido pleno, del monte. Con la primera se intenta que las prescripciones silvícolas contenidas en los pliegos de subastas sean seguidas con una cierta rigidez, sobre todo en lo relativo a la cantidad máxima de corcho (en ocasiones también mínima) que se puede obtener en cada pela y a la obligación de desbornizamiento de un determinado número de alcornoques. El objetivo es que en cada aprovechamiento sea predecible la cantidad de corcho que se puede obtener y que ésta aumente progresivamente al igual que la calidad y calibre de la materia prima.

La certeza de que la regularización es necesaria es tan constante como el convencimiento de que se falla en el seguimiento de las operaciones que pueden hacerla posible. En ocasiones la prueba de la culpa recae en la comunidad vecinal y en esas funciones vernáculas que el monte conserva. Así, la memoria de 1915 del Distrito Forestal de Santander alude al monte Ampudia como que en él

[...] todo el corcho segundero es viejo y de distintas edades que prueban que el descorche que los alcornoques han sufrido ha sido sin obedecer a plan en épocas diferentes para atender probablemente a pequeñas necesidades de los pueblos, viéndose en estos por ejemplo colmenas y algunas techumbres de chozas para las que se ha empleado el corcho. (ADGB, caja Corcho, legajo 12, 1915)

La situación particular de este monte es, a juicio del ingeniero que firma la memoria, tan extendida que concluye con la contundente afirmación de que «creemos por lo tanto que sea inútil cuanto se haga por conseguir la explotación regular del corcho en esta provincia» (ADGB, caja Corcho, legajo 12, 1915). Parece difícil asignar a esas pequeñas necesidades un poder condicionante tan grande. Las noticias que el sobreguarda de Liébana da en su informe de 1932 son más esclarecedoras. Se refiere también al monte Ampudia, aunque

[...] en este monte como en los anteriores hubo una subasta por catorce años y mi antecesor no los obligó al exacto cumplimiento del pliego de condiciones y lo sacaron salteado y de tal mala manera que para establecer nuevos turnos hay que hacer un intensísimo reconocimiento al efecto, así que hay varias épocas de descorche todo hecho en totum revolutum. (ADGB, caja Corcho, legajo 12, 1932)

Es más, en ocasiones la administración contribuye, aunque puede que sea consecuencia directa de ella, a la irregularidad en la producción de corcho a través de la autorización de aprovechamientos extraordinarios. En 1935, los industriales corcheros de Liébana Antonio de Paz (de Potes y propietario de La Bienganada) y Justo Aldana (de Puente Ojedo) solicitan al distrito forestal una subasta extraordinaria de corcho. La solicitud la basan en que

[...] sus respectivas industrias carecen de materia prima para continuar abiertas sus fábricas, por lo que tendrán que ir al paro forzoso las doce familias que de manera permanente viven de esta industria, a más de los jornales parciales que se reparten en la región por las operaciones de descorche, arrastre, etc. También se les irrogará perjuicios si paralizan su industria por la pérdida de mercados y piden que la subasta de corcho que solicita el pueblo de Frama del Ayto. de Cabezón de Liébana para el plan forestal de 1935-1936 sea concedido como subasta extraordinaria y poder hacer la pela durante el corriente verano [1935] ya que el corcho que se trata de aprovechar tiene 15 años y cuanto más pase el tiempo adquiere calidad maderosa que pierde esponjosidad y calidad para fabricar tapones. (ADGB, caja Corcho, legajo 12, 1935a)

Unos pocos años más tarde, en 1938 y con motivo de otra petición de subasta extraordinaria, se pone sobre el papel la misma valoración: «[...] en todos ellos [los montes alcornocales de Liébana] se ha llevado un aprovechamiento de forma bastante irregular, atendido más a la obtención del producto que a la regularización y mejora del monte» (ADGB, caja Corcho, legajo 12, 1938) (Fig. 4) ${ }^{19}$.

Con una perspectiva, la que da el paso del tiempo, la propuesta de ordenación realizada en el año 2004 sintetiza con finura la historia silvícola y cultural de estos alcornocales. Si bien alude sólo al monte Hinojedo de Cahecho, su apreciación se puede extender a gran parte de los montes lebaniegos: «[...] parecen objeto de una entresaca corchera, en la que se obtiene un producto de tamaño y calidad específica, más que un descorche generalizado ligado a un tranzón o área de descorche» (Castañedo, 2004, p. 45).

\footnotetext{
${ }^{19}$ En este caso, la petición de subasta extraordinaria la hacía el propio Distrito a instancia de los pueblos. En 1937, la entrada en Potes de las tropas sublevadas desbarata la industria corchera al tener que huir Antonio de Paz y Justo Aldana y los pueblos quedarse sin compradores. En la petición también se menciona que con una subasta extraordinaria se pueden abrir de nuevo las industrias ya que hay noticias de una persona interesada en hacerse con ella. Sin embargo, parece que todo el utillaje sufre el expolio de significados falangistas de Potes. El aprovechamiento de corcho es adjudicado en 1938 a un súbdito alemán afincado en Bilbao, Philipp Niegeman.
} 


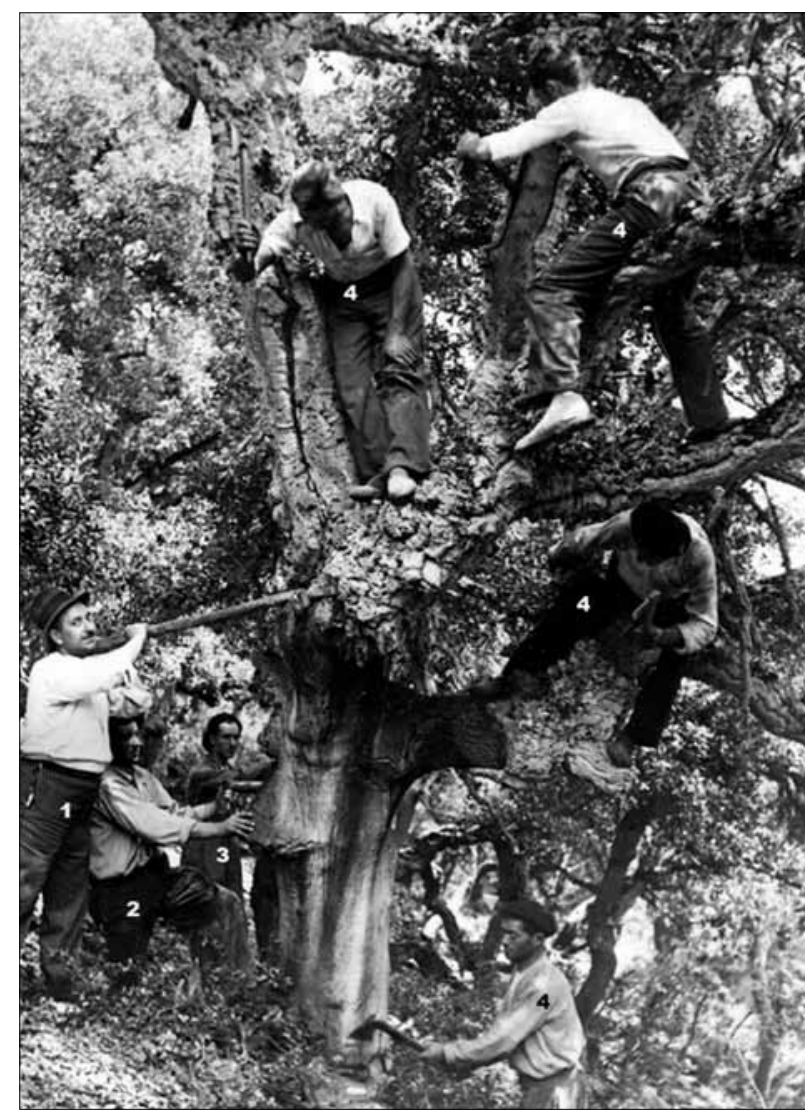

FIG. 4. Descorche del monte Ampudia (Cambarco) en 1934. 1. Antonio Paz Díez, propietario de La Bienganada; 2. Justo Aldana, taponero de Puente Ojedo; 3. Carlos Aldana, aspirante a guarda forestal; 4. operarios sin nominar (Archivo de la Dirección General de Biodiversidad del Gobierno de Cantabria).

Uno de los inconvenientes de los montes lebaniegos es su reducida extensión. Ésta dificulta o hace inviable establecer en ellos diferentes cuarteles de aprovechamiento corchero. A mediados de los años treinta del pasado siglo se plantea que, para que la regularización sea posible, debe superar la escala del monte, y extenderse a la de la comarca; es decir, considerar el conjunto de los alcornocales lebaniegos como una única entidad productiva. Este novedoso planteamiento para Liébana aparece expuesto por primera vez en 1934. El ingeniero Julio Santos, que tiene a su cargo los montes de la comarca, solicita fondos para realizar un estudio en veinte montes «que permita regularizar el aprovechamiento del corcho y aumentar su valor». En la defensa de esta necesidad coincide con los argumentos que ya se han expuesto:

[...] los aprovechamientos se han realizado de manera completamente irregular, resultando de ello que la mayoría de los sitios de un mismo monte se encuentran árboles sin desbornizar, otros que han sufrido una pela y algunos hasta dos, forma de aprovechamiento verdaderamente anárquica que dio el resultado de obtener en montes limítrofes 800 quintales del país de 36.000 alcornoques y 500 de 3.600 alcornoques, lo que solamente puede explicarse por la forma irregular y caprichosa de aprovecharse estos montes.

Es más, según él esa irregularidad es responsable de la pequeña entidad de la industria corchera en Liébana. De esas instalaciones afirma que

$[\ldots]$ son rudimentarias $[\ldots]$ y creemos que su pequeño incremento puede ser debido, muy principalmente, a la irregularidad con que se surten de materia prima, pues mientras algunos años han tenido gran abundancia de ella, trasladando gran parte del corcho a Cataluña, en otros no han tenido para cubrir sus necesidades. (ADGB, caja Corcho, legajo 12, 1934) ${ }^{20}$

No sabemos si el estudio finalmente se realiza y si de alguna forma influye en que en 1946 se subaste de una sola vez el aprovechamiento de corcho de todos los montes de Liébana para el periodo forestal comprendido entre 1946-1947 y 1959-1960 y que a su conclusión sea reiterada la necesidad de hacer otra subasta similar para los años de 1960-1961 a 1973-1974 (ADGB, caja Corcho, legajo 12, 1959b). Lo cierto es que se establece como condición el que se deben descortezar todos los alcornoques con más de $60 \mathrm{~cm}$ de perímetro, ya fuesen bornizos o segunderos, con el objeto de obtener una cierta regularización de producciones y calidades. Más allá de esta última, no hay otra subasta similar. A partir de 1972 se procede a redactar los proyectos de ordenación de los montes de uP de Liébana, entre los que se incluyen todos los que poseen el alcornoque entre sus existencias. Se abandona la regularización por la vía de pequeños planes dasocráticos y con los nuevos proyectos de ordenación, vigentes para el periodo 1971-1972 a 1982-1983, se retoma la dinámica de las subastas individuales para el aprovechamiento del corcho de cada monte.

\section{El alCORNOQUE Y EL CORCHO: LA MARGINALIDAD FRENTE A OTRAS SILVICULTURAS Y PRIORIDADES}

Las propuestas de regularización en Liébana, es decir, el intento de aprovechar ordenadamente el corcho con objeto de dar valor a este producto, aumentar los

\footnotetext{
${ }^{20}$ Con la alusión a la venta a Cataluña sin duda se está refiriendo a los acuerdos comerciales de Antonio de Paz y Cástor del Río con la Gran Serrinera Catalana de Corcho La Lolita, de Arenys de Mar.
} 
ingresos de los propietarios de los montes, proporcionar jornales y un futuro a las pequeñas industrias transformadoras, saca a la luz, en su momento, otra realidad del corcho cántabro. Es la de que al alcornoque «se considere en la región como la de menos valor entre las que pueblan los montes» (ADGB, caja Corcho, legajo 12, 1934). El escaso valor se debe a las limitaciones estructurales que para el desarrollo del negocio corchero introduce la pequeña extensión de los alcornocales, su ubicación y décadas de aprovechamientos irregulares. Pero también ese escaso valor tiene un componente relativo que depende de la entidad y magnitud del resto del negocio forestal en Cantabria.

El desarrollo el negocio corchero en Liébana coincide, a grandes rasgos, con el de nacimiento y consolidación de la moderna administración forestal. Con pocos medios y muchos frentes, el grueso de las iniciativas del distrito forestal de Santander se dirigen inicialmente a salvaguardar el patrimonio forestal público, a las operaciones de deslinde y amojonamiento, a la regularización y control de los aprovechamientos, más tardíamente a la ordenación de montes y, por último, a los trabajos de repoblación forestal. En este contexto no es extraño que aprovechamientos y actividades de escaso peso, por más que a escala local tengan un cierto significado, no conciten actuaciones de ordenación y mejora decididas y continuadas en el tiempo.

Un ejemplo del peso real que el ecosistema corchero lebaniego tiene en la realidad forestal de Cantabria es el que se infiere de la Memoria general de repoblación del Distrito de Santander (AmA, Repoblaciones, deslindes y amojonamientos, expediente 394-6, 1880). Este documento, al igual que el resto de las que se envían al Ministerio de Fomento entre 1878 y 1884 como consecuencia de las disposiciones que desarrollan la Ley de 11 de junio de 1877 sobre Repoblación, fomento y Mejora de los Montes Públicos, contiene, además de las actuaciones que los distritos proponen para dar cumplimiento al objetivo de la ley, un diagnóstico de la situación de los montes y las grandes orientaciones de la política forestal que se pretenden desarrollar en ellos. Las referencias al alcornoque son pocas, y más aún si se comparan con las que aparecen de otras especies e industrias; tan sólo se señala su fácil propagación y que su explotación es una potencialidad para la industria que transforma su corteza.

La totalidad de las actuaciones y mejoras que se sugieren pretenden reforzar el perfil maderero de Cantabria. Es más, en este momento ya han hecho acto de presencia, aunque tímidamente, especies que concentran, por sus extraordinarios rendimientos y el volumen de rentas que generan, una atención notablemente mayor. Son las especies de crecimiento rápido, necesitadas de una silvicultura intensiva, que incluso en ocasiones, como ocurre con el pino de Monterrey en Liébana, llega a competir físicamente con los alcornocales por las mismas ubicaciones, cálidas y húmedas ${ }^{21}$.

\section{CONCLUSIONES}

Los ocasionales descorches de los alcornocales lebaniegos insertan estos montes, a pesar de su escasa superficie, dentro del contexto productivo marcado por el aprovechamiento taponero e industrial del corcho que se extiende por toda España, más allá de Cataluña, a partir del segundo tercio del siglo XIX. Pero también, las escasas cantidades de corteza que se extrae en la actualidad disimulan tanto el significado local que tiene el negocio corcho-taponero hasta hace unas pocas décadas como el discurso sobre las posibilidades de enriquecimiento individual y colectivo que lo acompaña en ese mismo intervalo de tiempo.

La génesis del negocio corcho-taponero tiene en Liébana rasgos singulares. En ese nacimiento no parecen tener ningún protagonismo los industriales catalanes que, en su búsqueda de nuevas abastecedoras dada la rigidez de la oferta de corcho de sus alcornocales, extienden las lógicas y las claves de aquel negocio por el oeste de España a partir de 1835. Esta función recae, y aún más tempranamente que sus homólogos catalanes, en comerciantes franceses que hacen su aparición en la comarca a lo largo de las dos primeras décadas del siglo XIX y necesitados de corcho para el abastecimiento de los talleres de Aquitania. El papel que desempeñan, no obstante, parece que trasciende el del mercadeo del corcho: de franceses son también los primeros talleres taponeros lebaniegos. A partir de ese momento y hasta 1937, fecha en la que desaparece la elaboración de géneros corcheros, se conforma una actividad transformadora que no pierde nunca un perfil artesanal y cuya escasa entidad es un reflejo de las fuertes limitaciones que la ubicación, extensión y características silvícolas de los alcornocales lebaniegos tienen para una producción de corcho abundante y de calidad.

\footnotetext{
${ }^{21}$ Los primeros eucaliptos llegan a Santander hacia 1863 (Barreda, 1961). Aunque con algunas reticencias iniciales por parte de los forestales santanderinos, pronto concitó esta especie un importante interés, sobre todo después de los buenos resultados de las plantaciones de 1880
} 
La ubicación es un rasgo estructural, pero no así, o por lo menos no completamente, la extensión y las características silvícolas. La documentación no muestra ni que la primera haya cambiado sustancialmente ni que las segundas hayan sido dirigidas a mejorar la producción de corcho a lo largo del período de tiempo analizado en este trabajo. Es decir, el ser montes de utilidad pública y estar encomendada su gestión a la administración forestal no ha supuesto mejorar las capacidades de estos alcornocales como productores de corcho. De hecho, todo el periodo estudiado se caracteriza por una irregularidad, variable en su intensidad, en los aprovechamientos y por la consolidación más de una entresaca corchera que de un aprovechamiento ordenado.

Industria y administración operan sobre un espacio fuertemente vinculado a tradiciones comunales de base concejil. De hecho, la integración capitalista e industrial del corcho en Liébana parece que refuerza con el tiempo el vínculo entre los montes y las comunidades que los poseen. Éstas despliegan, sobre todo a partir del último cuarto del siglo XIX (momento en el que se establece la subasta como forma de adjudicación del aprovechamiento del corcho) una intensa resistencia a algunos de los contenidos de los pliegos que las regulan y a una creciente intervención por parte de la administración forestal.

Hoy en día, abandonada la transformación y reducida la extracción, se impone sobre los alcornocales lebaniegos una lectura eminentemente patrimonial, aunque acantonada en su singularidad geobotánica. Esa lectura, para ser completa, debe añadir otras connotaciones: la reconstrucción de cómo se levanta un pequeño espacio corchero en Cantabria.

\section{FUENTES Y BIBLIOGRAFÍA}

\section{1) Fuentes}

Archivo Diocesano de Santander (ads)

- 1757 a 1836, Potes, Libro de Bautizos, signatura 944.

- 1839 a 1853, Potes, Libro de Bautizos, signatura 945.

Archivo Histórico Provincial de Cantabria (AhPCa) Sección Diputación, serie Montes

- Legajo 7, núm. 2 (numeración antigua), 1851, Regencia de la Audiencia Territorial de Burgos. Causa criminal contra D. Pedro Irigoyen sobre extracción de corchos y descortezo de ciento veinte pies de alcornoque.

- Legajo 16, diversos años, estados del arbolado.
Archivo de la Dirección General de Biodiversidad. GoBIERNO DE CANTABRIA (ADGB)

Caja Corcho, legajo 12:

- (1915): Memoria sobre el aprovechamiento del corcho.

- (1932): Informe sobre el corcho y los alcornocales de Liébana del sobreguarda de Puente Ojedo al ingeniero del Distrito.

- (1934): Presupuesto para la regularización de los aprovechamientos de corcho en los montes $n^{\circ} .117,66$ y 65 del Catálogo de los de utilidad de esta provincia, situados en la región de Liébana.

- (1935a): Carta de Antonio Paz solicitando una corta extraordinaria de corcho.

- (1935b): Informe del ingeniero jefe del distrito sobre la petición de corta extraordinaria.

- (1938): Petición del Distrito Forestal de Santander al jefe del Servicio Nacional de Montes, Caza y Pesca Fluvial de un aprovechamiento extraordinaria de subasta de corcho.

- (1946a): Pliego de la subasta del aprovechamiento de corcho de los montes de Liébana.

- (1946b): Acta de la subasta de corcho del 25 de octubre de 1946.

- (1955): Carta de Nicanor Fombellida al ingeniero Julio Santos de 3-XII-1955.

- (1957): Petición de información al Distrito Forestal de Málaga sobre precio del corcho, 25-XI-1947.

- (1958a): Carta de la Junta Vecinal de Frama al gobernador civil de Santander de 30-XII-1958.

- (1958b): Propuesta de revisión del precio de corcho correspondiente a los aprovechamientos de los años forestales 1957/58, 1958/59 y 1959/60.

- (1959a): Carta de la Jefatura al Gobierno Civil.

- (1959b): Memoria y presupuesto para llevar a cabo la ordenación provincial del aprovechamiento de corcho en los montes números 63, 64, 66, 69, 70, 71, 72, $74,75,76,77,86,97,107,117,130,131,135$ y 137 del catálogo durante los años 1960-61 a 1973-74.

Archivo de la Cámara Oficial de Comercio e Industria DE CANTABRia (COCICAN)

- Censos repartimiento, desde el año 1926 a 1937.

Archivo Histórico Ferroviario (AHF)

Transporte de corcho, 1909 a 1941. D-0199-010, exp. 16.

- (1930): Corcho de la provincia de Santander para Cataluña.

Archivo del Ministerio de Agricultura (ama)

Fondo Montes, siglo XIX 
Caja 395-b, exp. 11

- (1884): Expediente promovido por los alcaldes de barrio de los pueblos de Frama y Cambarco, pertenecientes al ayuntamiento de Cabezón de Liébana, relativo al aprovechamiento de corcho de los montes Cornejas, Ampudia y Reocín, año 1884.

Fondo Repoblaciones, deslindes y amojonamientos

Caja 394, exp. 6

- (1878): Expediente sobre la realización de la memoria general y mejora de los montes púbicos de la provincia de Santander.

Fondo Planes de Aprovechamientos Forestales. Diversos años entre 1896 y 1908.

- Legajos 4/2; 7/3; 10/9; 15/3; 20/3; 24/10; 29/4; 33/9; $36 / 2 ; 42 / 6 ; 46 / 12 ; 50 / 12 ; 55 / 2 ; 60 / 5 ; 65 / 6 ; 70 / 5 ; 81 / 4$; $86 / 2 ; 91 / 3 ; 97 / 5 ; 104 / 3 ; 111 / 1 ; 117 / 4 ; 124 / 4 ; 136 / 4$; $147 / 5 ; 186 / 8$.

\section{2) BibLIOGRAFÍA}

Aedo, C., C. Diego, J. C. García y G. Moreno (1990): El bosque en Cantabria. Universidad de Cantabria/ Asamblea Regional de Cantabria, Santander.

Alvarado, J. (2002): El negoci del suro a l'Alt Empordà (s. XVIII-XIX). Museu del Suro, Palafrugell.

Anuario de Estadística de España. Años 1972 a 2004, Instituto Nacional de Estadística, Madrid.

Anuario de Estadística Forestal. Años 2005 a 2010. Ministerio de Medio Ambiente, Rural y Marino, Madrid.

Arbeu, P. (2012): La Sociedad Económica de Amigos del País de Liébana en el siglo XIX. Bubok Publishing.

BERTRAND, G. (1964): «Esquisse biogéographique de La Liebana (massif cantabrique, Espagne): la dynamique actuelle des paysages». Revue Géographique des Pyrénées et du Sud-Ouest, t. 33-3, pp. 225-262.

CAmpos, J., y R. LANZa (1985): Paisaje rural y estructuras agrarias en un concejo lebaniego, $s$. XVIII. Ediciones Tantín, Santander.

CASAls, V. (1996): Los ingenieros de montes en la España contemporánea 1848-1936. Ediciones del Serbal, Barcelona.

Castañedo, V. (2004): Proyecto de ordenación del muP $n .^{\circ}$ 64, perteneciente al pueblo de Cahecho, en $\mathrm{Ca}$ bezón de Liébana (Cantabria). Universidad de León/ Escuela Superior y Técnica de Ingeniería Agraria, León.

Catálogo de los productos agrícolas presentados a la Exposición de 1857. Imprenta Nacional, Madrid, 1857.

Costa, M., C. Morla y H. Sainz (eds.) (1997): Los bos- ques ibéricos. Una interpretación geobotánica. Planeta, Barcelona.

Díaz, P. M., M. I. Gallardo y L. Gil (1996): «Alcornocales marginales en España. Estado actual y perspectivas de conservación de un recurso genético». Revista Ecología, 10, pp. 21-47.

DíEz, A. B. (2002): Asistencia técnica para el análisis, planificación y gestión de las masas de Quercus suber $L$. en la comunidad autónoma de Cantabria. Dirección General de Montes, Santander, documento inédito.

Estadística de la producción de los montes de utilidad pública de España. Años 1910 a 1933. Dirección General de Agricultura, Industria y Comercio, Madrid.

Estadística forestal de España. Años 1940 a 1971. Dirección General de Montes, Caza y Pesca Fluvial, Madrid.

Exposición Nacional Vinícola de 1877. Catálogo general. Imprenta, estenotipia y galvanoplastia de Aribau y C. ${ }^{\text {a }}$, Madrid, 1877.

EzqueRRa, F. J., y L. GiL (2004): La transformación histórica del paisaje forestal en Cantabria. Ministerio de Medio Ambiente, Madrid.

Gómez, J. (1992): Ciencia y política de los montes españoles (1848-1936). Icona, Madrid.

Guinea, E. (1953): Geografía botánica de Santander. Diputación Provincial, Santander.

JiMÉNEZ, J. I. (1999): «La oferta de corcho en los montes públicos españoles (1900-1933)», en A. Parejo y A. Sánchez (eds.): Economía andaluza e historia industrial. Estudios en homenaje a Jordi Nadal. Universidad de Almería/Unicaja, Almería.

- (2009): «El comercio corchero de los Estados Unidos (1900-1960): los países proveedores», en S. Zapata (edt.): Alcornocales e industria corchera: hoy, ayer y mañana. Museu del Suro de Palafrugell, Palafrugell.

- (2013): «Un siglo de innovación en la saca de corcho». Revista de Historia Agraria, 61.

La Voz de LiéBana (1907): Noticia relativa a la Sociedad Económica de Amigos del País. 20 de octubre.

- (1913): Liébana y los Picos de Europa. Ligera reseña histórica. Datos geográficos y estadísticos. Itinerarios, Monumentos y Santuarios. Costumbres. Lebaniegos ilustres. Establecimiento Tipográfico de La Atalaya, Santander.

- (1922): Noticia relativa a los incendios de los montes. 15 de octubre.

- (1923): Noticia relativa al incendio del monte Vicobres y Valcaliente. 15 de agosto.

- (1927): Noticia relativa al incendio del monte Valmayor. 17 de octubre.

- (1928): Noticia relativa a los montes. 31 de mayo. 
LAMADRID, M. (1836): Memoria sobre los grandes montes y demás riquezas de Liébana. Imprenta de D. Timoteo Arnáiz, Burgos.

LANZA, R. (1988): Población y familia campesina en el Antiguo Régimen. Liébana, siglos XVI-XIX. Universidad de Cantabria y Ediciones de la Librería Estudio, Santander.

LloRente I. (1882): Las cacerías del rey. Descripción del viaje que en el verano de 1882 hizo el rey don Alfonso XII a los Picos de Europa y a Liébana. Imprenta de José Gil y Navarro, Madrid.

MAPA Forestal de EsPaña (MFE) (2003): Comunidad autónoma de Cantabria y provincias de Ávila, León, Lugo, Ourense, Pontevedra, Salamanca, Valladolid y Zamora. Serie Técnica, formato digital. Organismo Autónomo de Parques Nacionales, Madrid, escala 1:50.000.

Medir, R. (1953): Historia del gremio corchero. Alhambra, Madrid.

Memoria sobre el estado de la industria de la provincia de Santander. Año 1904. Dirección General de Agricultura, Industria y Comercio, Madrid, 1905.

PARejo, F. M. (2010): «El negocio del corcho en España durante el siglo Xx». Estudios de Historia Económica (Banco de España, Madrid), 5.

- C. M. Faísca y J. F. Rangel (2013): «Los orígenes de las actividades corcheras en Extremadura: el corcho extremeño entre catalanes e ingleses». Revista de Estudios Extremeños, LXIX, 1, pp. 462-489.

Puyo, J. Y. (2010): «Les suberais d'Aquitaine: entre enjeux patrimoniaux et relance èconomique». Revue Sud-Ouest Europèen, núm. 30, pp. 53-66.
SALA, P. (1998): «Obrador, industria i aranzels al districte surer català (1830-1930)». Recerques, 37, pp. 109136.

SANZ, J. (1985): «La historia contemporánea de los montes públicos españoles, 1812-1930. Notas y reflexiones», en R. Garrabou y J. Sanz (eds.): Historia agraria de la España contemporánea. Vol. 2. Expansión y crisis (1850-1900). Crítica, Barcelona, pp. 193-228.

Sociedad Económica de Amigos del País de Liébana (SEAPL) (1841): Memoria de los trabajos y proyectos de la Sociedad Económica de Amigos del País de Liébana en su año social de 1840 al 41 leída en Junta General de 20 de junio, e impresa por acuerdo de la misma. Imprenta de D. Eusebio Aguado, Madrid.

- (1909): Memoria de los trabajos y proyectos de la Sociedad Económica de Amigos del País de Liébana durante el año social de 1908 a 1909. Imprenta de La Voz de Liébana, Potes.

ZAPATA, S. (1986): «El alcornoque y el corcho en España, 1850-1935», en R. Garrabou, C. Barciela y J. I. Jiménez (eds.): Historia agraria de la España contemporánea. Vol. 3. El fin de la agricultura tradicional (1900-1960). Crítica, Barcelona, pp. 230-279.

- (1996): Corcho extremeño y andaluz, tapones gerundenses. Revista de Historia Industrial, 10, pp. 37-67.

- (2009): «Declive y resistencia de la industria corchera española en la segunda mitad del siglo Xx. Una descripción cuantitativa», en S. Zapata (ed.): Alcornocales e industria corchera: hoy, ayer y mañana. Museu del Suro de Palafrugell, Palafrugell, pp. 840-874. 